Article

\title{
In Vitro Screening of Molecularly Engineered Polyethylene Glycol Hydrogels for Cartilage Tissue Engineering using Periosteum-Derived and ATDC5 Cells
}

\author{
Abhijith K. Kudva 1,2,3, Frank P. Luyten ${ }^{2,3}$ and Jennifer Patterson $1,2,4, *$ (D) \\ 1 Department of Materials Engineering, KU Leuven, Kasteelpark Arenberg 44, Box 2450, 3001 Leuven, \\ Belgium; akudva19@utexas.edu \\ 2 Prometheus, Division of Skeletal Tissue Engineering, KU Leuven, O\&N 1, Herestraat 49, Box 813, \\ 3000 Leuven, Belgium; frank.luyten@uzleuven.be \\ 3 Skeletal Biology and Engineering Research Center, KU Leuven, Herestraat 49, Box 813, \\ 3000 Leuven, Belgium \\ 4 Oral and Maxillo-facial Surgery-Imaging \& Pathology (OMFS-IMPATH), KU Leuven, \\ Kapucijnenvoer 7 block a, Box 7001, 3000 Leuven, Belgium \\ * Correspondence: pattersn@alumni.princeton.edu; Tel.: +32-495-615928
}

Received: 19 September 2018; Accepted: 22 October 2018; Published: 26 October 2018

check for updates

\begin{abstract}
The rapidly growing field of tissue engineering and regenerative medicine has brought about an increase in demand for biomaterials that mimic closely the form and function of biological tissues. Therefore, understanding the cellular response to the changes in material composition moves research one step closer to a successful tissue-engineered product. With this in mind, polyethylene glycol (PEG) hydrogels comprised of different concentrations of polymer $(2.5 \%, 4 \%, 6.5 \%$, or $8 \%$ $(w / v))$; different protease sensitive, peptide cross-linkers (VPMSMRGG or GPQGIWGQ); and the incorporation or lack of a peptide cell adhesion ligand (RGD) were screened for their ability to support in vitro chondrogenesis. Human periosteum-derived cells (hPDCs), a mesenchymal stem cell (MSC)-like primary cell source, and ATDC5 cells, a murine carcinoma-derived chondrogenic cell line, were encapsulated within the various hydrogels to assess the effects of the different formulations on cellular viability, proliferation, and chondrogenic differentiation while receiving exogenous growth factor stimulation via the medium. Through the results of this screening process, the $6.5 \%(w / v)$ PEG constructs, cross-linked with the GPQGIWGQ peptide and containing the RGD cell binding molecule, demonstrated an environment that consistently supported cellular viability and proliferation as well as chondrogenic differentiation.
\end{abstract}

Keywords: polyethylene glycol; ATDC5; periosteum-derived mesenchymal stem cells; chondrogenesis; hydrogels; matrix metalloproteinase

\section{Introduction}

The classical combination of cells, biomaterial scaffolds, and biomolecules is a main premise of tissue engineering strategies being explored to regenerate, repair, or replace compromised tissues and organs resulting from trauma, disease, or everyday wear and tear [1]. This approach first entails the isolation of tissue appropriate cells, followed by the expansion of the cells to the desired amount, their combination with biomaterial scaffolds and/or stimulatory factors, additional in vitro culture, and finally the implantation of the tissue-engineered construct into the host's body to help heal the damaged tissue. Biomaterials are of particular importance in this process as they provide biochemical 
or mechanical cues to the cells in the tissue-engineered construct. These characteristics can also facilitate the reduction of the host response and improve tissue regeneration. An ideal biomaterial based scaffold should be temporary in nature and should support the initial stages of de novo tissue formation. One approach in scaffold design is to imitate aspects of the biological tissue to be regenerated, for example by trying to replicate the local extracellular matrix (ECM) [2]. The ECM is a sophisticated network of proteins and polysaccharides in the interstitial space that provides structure to the tissue; supports cell signaling; and influences the transport, sequestration, and presentation of biochemical cues such as growth factors. The composition of the ECM is highly tissue-specific, meaning that each type of tissue has its own ECM comprised of different proteins, polysaccharides, and signaling molecules that are vital for that particular tissue's morphogenesis.

In that regard, several decades of research have been conducted emphasizing the use of biomaterials, more specifically hydrogels, for cartilage tissue engineering and regeneration [3]. Hydrogels are 3D hydrophilic networks that can imbibe large amounts of water, which is a major component of the native cartilage ECM [4], and can further be tailored to reproduce other chemical and mechanical properties of cartilage tissue. In addition, they can permit suitable nutrient and waste transportation, which is crucial for cell growth and survival. Hydrogels for tissue engineering applications can be designed from materials that are natural, synthetic, or a combination of both $[5,6]$. For the research reported herein, polyethylene glycol (PEG), a synthetic polymer, is used as the base material for the hydrogels. Although PEG is relatively inert biologically, it can be combined with bioactive components such as matrix metalloproteinase (MMP)-sensitive peptide linkages or cell adhesion ligands, and these systems have demonstrated the engineered biological activity and proved advantageous for tissue engineering applications [7]. PEG hydrogels fabricated using different chemistries have been extensively studied, and the influence of composition on the controlled variation of properties such as degradation rate, stiffness, and bioactivity have previously been demonstrated. The cross-linking density and mechanical properties of PEG hydrogels can be easily manipulated not only via the amount of cross-linker used but also by altering the concentration or structure of the PEG macromer $[8,9]$. For example, for cartilage tissue engineering, degradable PEG di-methacrylate (PEG-DM) hydrogels combined with a degradable poly(lactic-acid)-PEG-poly(lactic-acid) copolymer led to increased collagen type II synthesis and a more homogenous distribution of glycosaminoglycans (GAGs) produced by encapsulated bovine chondrocytes [10]. Further, PEG hydrogels with lower cross-linking densities have given rise to enhanced ECM production by both chondrocytes [10,11] and mesenchymal stem cells (MSCs) [12].

For the scope of this work, we aimed to test PEG hydrogels formed via the step growth mechanism of the Michael-Type addition reaction. The Michael-Type addition reaction involves nucleophilic addition to unsaturated electrophiles. To form the PEG hydrogel network, multi-arm, end-functionalized PEG macromers, such as vinyl sulfone end-functionalized PEG (PEG-VS), are cross-linked with peptide protease substrates that contain cysteine residues with reactive thiol groups (thiolates) at either end [13]. This approach is attractive as the reaction takes place at near physiological $\mathrm{pH}$ and temperatures and has been demonstrated to be selective for the thiol groups in the cross-linker molecules compared to biological amines [14]. Further, peptides containing greater than two reactive groups can be incorporated to form elastically-active network chains as part of a cross-linked 3D structure [13]. The 3D network that is formed can be varied based on several factors. The size of the PEG macromer $\left(M_{\mathrm{W}}\right)$, the precursor concentration, and the number of end-functionalized branched arms present on the PEG play an important role in network formation and the properties of the resulting hydrogels. The mass swelling ratio is one property of hydrogels that provides information on the structure of the cross-linked network that is formed, including mesh size [15]. For these Michael-Type addition hydrogels, it has been demonstrated that, by increasing the $M_{\mathrm{W}}$ of the PEG, the equilibrium mass swelling ratios of the cross-linked networks increased irrespective of the dithiol cross-linker used [7,16]. Furthermore, as the concentration of the precursor solution increased prior to cross-linking, the resulting hydrogels' equilibrium mass swelling ratio decreased, which was concluded to be a result of the intramolecular reactions being favored at low precursor concentrations whereas intermolecular cross-links were favored at high concentrations [16]. 
At the same time, it was shown that the elastic moduli of the hydrogels increased with increasing PEG concentration, irrespective of the $M_{\mathrm{w}}$, although the hydrogels formed from macromers with higher $M_{\mathrm{w}}$ displayed a lower elastic modulus at the same precursor concentration [13]. Moreover, for degradable hydrogels, as the $M_{\mathrm{w}}$ of the PEG macromer increased, the initial swelling ratio increased along with the apparent rate of degradation due to the increase in water content [16]. Similar MMP sensitive PEG-VS (4-arm, $20 \mathrm{kDa}$ ) hydrogels to those used herein have been characterized in previous studies and have displayed an average mesh size of approximately $0.025 \mu \mathrm{m}$ and a storage modulus of close to $300 \mathrm{~Pa}$ for the composition of $10 \%(w / v)$ macromer [17].

In addition to the PEG macromer playing a role in the hydrogel properties, the dithiol peptide cross-linker utilized also has an impact. For instance, by altering the local electrostatic environment of the thiol by increasing its proximity to an additional charged amino acid and decreasing its dissociation constant $(p K a)$, the gelation rate increased [13]. Moreover, the sequence of the particular amino acids present in the degradable peptide cross-linker had an influence on the overall degradation rate of the hydrogel $[7,18]$. The kinetic parameters $\left(K_{\mathrm{m}}\right.$ and $\left.k_{\text {cat }}\right)$ determined via Michaelis-Menten analysis of the degradation of individual peptide cross-linkers by specific MMPs correlated well with the degradation rate of hydrogels formed with these protease substrates by the same enzymes $[18,19]$. To build upon past research, herein we have specifically varied the composition of the PEG hydrogels through the use of different amounts of PEG $(2.5 \%, 4 \%, 6.5 \%$, and $8 \%(w / v))$; different peptide sensitive cross-linkers (GPQGIWGQ vs. VPMSMRGG), varying in their degradation rates [19]; and lastly, different amounts of the cell binding motif, RGD, covalently bound in the PEG hydrogels. These various hydrogels were screened by encapsulating either human periosteum-derived cells (hPDCs), which are primary MSC-like cells, or ATDC5 cells, a cell line derived from mouse carcinoma.

The cells in the periosteum are a source for the osteoblasts that enable appositional bone growth during bone homeostasis and, in combination with osteoclasts, help the remodeling of cortical bone [20]. The inner cambium of the periosteum also serves as a main source of progenitor cells during fracture healing [20], and the PDCs harvested and expanded from this tissue have demonstrated high proliferative capacity and multilineage potential [21-23]. PDCs have also displayed osteochondrogenic potential in vivo, when seeded on 3D calcium phosphate scaffolds [24]. Additionally, hPDCs have shown chondrogenic potential when cultured in vitro in micromass conditions [25] as well as when encapsulated within 3D hydrogels [26], thus making them an attractive cell source for skeletal tissue engineering. On the other hand, as with other adult stem cells, harvesting of PDCs also has shortcomings. Although harvesting tissue from this region could alter tissue homeostasis, PDCs possess a high proliferative capacity and hence a relatively small biopsy would be required. Furthermore, the harvest of small tibial periosteal flaps has been FDA approved for autologous chondrocyte implantation (ACI) [27].

While MSCs and PDCs would seem ideal for use in tissue engineering strategies, some of the drawbacks associated with the use of primary cells, such as donor availability and/or donor variability, have prompted in vitro investigation with more reproducible cell lines. Immortalized cell lines demonstrate advantages such as infinite, homogenous proliferation as well as consistent differentiation as they are composed of a pure population of cells [28]. Furthermore, cell lines are easy to use and cost effective, and they avoid the ethical concerns that accompany the use of primary animal or human cells. These characteristics make cells lines a very attractive source when evaluating biomaterials as they help to make in vitro testing facile and reproducible.

The cell line used in this study, ATDC5, was derived from AT805 mouse teratocarcinoma fibroblastic cells and established by Atsumi et al. as a promising in vitro model to study chondrogenesis [29]. In 2D culture, these cells exhibited a fibroblastic cellular phenotype during the growth phase, and the subsequent introduction of insulin caused the cells to continue to grow past confluence and form aggregates resembling cartilaginous nodules with chondrogenic specific proteoglycan production [29]. Since then, additional in vitro studies have highlighted the value of ATDC5 cells for studying chondrogenesis. For instance, Shukunami et al. have shown that ATDC5 cells undergo a chondrogenic process in a sequential manner similar to chondrocyte differentiation [30,31]. During this chondrogenic 
process, ATDC5 cells have also displayed the Indian hedgehog (Ihh) [32] and parathyroid hormone (PTH)/parathyroid hormone receptor protein (PTHrP) [31] signaling pathways, which are key signaling pathways that determine the fate of chondrocytes. ATDC 5 cells in micromass, pellet, or aggregate cultures have been used to investigate the influence of various factors in cartilage tissue engineering strategies, for example, the effects of hypoxic conditions on chondrogenesis [33,34]. Furthermore, ATDC5 aggregates that were chondrogenically stimulated in vitro and implanted in vivo using a 3D scaffold showed signs of ectopic bone formation [35]. ATDC5 cells have also been cultured on synthetic polymer hydrogels with various charge densities [36]. By seeding ATDC5 cells on either a neutral poly(dimethylacrylamide) (PDMAAm) hydrogel or a negatively charged poly(2-acrylamido-2-methyl-1-propanesulfonic acid) (PAMPS) hydrogel, chondrogenic differentiation was induced in insulin-supplemented differentiation medium and in insulin-free maintenance medium, respectively [36]. Another study displayed high ATDC5 metabolic viability and proliferation when they were encapsulated within injectable, hyaluronic acid/PEG hydrogels [37].

Hence, in this study, we aim to harness the potential of hPDCs along with the well characterized ATDC5 chondrogenic cell line to screen the different PEG hydrogel formulations described above for their ability to support progenitor cell proliferation as well as chondrogenesis. For proliferation, the change in DNA content within the cell-laden constructs was measured, whereas to assess chondrogenic differentiation, the cellular glycosaminoglycan (GAG) production was analyzed, along with qualitative histological staining for GAG and collagen. Although we have previously demonstrated the ability of the $6.5 \%(w / v)$ PEG hydrogels functionalized with GPQGIWGQ and RGD peptides to support proliferation and chondrogenesis of hPDCs [26] as well as redifferentiation of 2D expanded human articular chondrocytes [38], the novelty of the present study is the more extensive variation of the PEG hydrogel compositions to further explore the influence of material properties on cell behavior as well as the evaluation of the behavior of ATDC5 cells in this hydrogel system.

\section{Results and Discussion}

\subsection{Screening Using hPDCs Encapsulated in PEG Hydrogels}

2.1.1. Hydrogel Composition Affects the Encapsulated hPDCs' Viability and Proliferation when Cultured in Growth Medium

Molecularly engineered hydrogels (see Table 1 for a summary of the compositions as well as nomenclature used) were made with the concentration of PEG ranging from $2.5 \%$ to $8 \%(w / v)$, variation in the type of peptide cross-linker incorporated, and the addition or lack of the cell binding ligand, RGD. In particular, the protease-sensitive peptide cross-linker varied in sequence between a substrate derived from type I collagen (GPQGIWGQ, referred to as the regular degrading cross-linker or R throughout) and a faster degrading cross-linker (VPMSMRGG, referred to as $\mathrm{F}$ throughout) [18,19]. In previous studies, the R cross-linker had measured $k_{\text {cat }}$ values of $0.65 \pm 0.13 \mathrm{~s}^{-1}$ and $2.17 \pm 0.16 \mathrm{~s}^{-1}$ with respect to MMP-1 and MMP-2 [19]. Additionally, it was shown that PEG hydrogels composed of the $\mathrm{R}$ cross-linker continued to persist longer than 10 days when incubated with MMP-1 but degraded after 4 days when incubated with MMP-2 [19]. Furthermore, the F cross-linker had significantly higher $k_{\text {cat }}$ values $\left(5.25 \pm 0.95 \mathrm{~s}^{-1}\right.$ for MMP-1 and $4.82 \pm 0.79 \mathrm{~s}^{-1}$ for MMP-2), when compared to the R cross-linker. The $k_{\text {cat }}$ value of the F cross-linker was also $3.79 \pm 0.62$ times higher than that of the $\mathrm{R}$ cross-linker for the enzyme plasmin [18]. Moreover, the hydrogels containing the F cross-linker also degraded significantly faster in the presence of MMP-1 and MMP-2 ( 1.5 and 2 days, respectively), when compared to the hydrogels comprised of the R cross-linker treated with these enzymes [19]. After 1 week of in vitro culture in growth medium (GM), the hPDCs encapsulated within the various hydrogel compositions displayed a good level of viability (Figure 1A), with no composition displaying a viability percentage of less than $75 \%$ (Figure 1C). Already at this time point, the hydrogels with the lowest concentration and the faster degrading cross-linker (2.5F0 and 2.5FR) were too degraded to be further handled, and thus these formulations were not able to be evaluated throughout the rest 
of the study. When observing the viability of the hPDCs in the PEG hydrogels after four weeks of in vitro culture in GM (Figure 1B), the cells in the hydrogels without any RGD demonstrated a drop in their viability, sometimes displaying a cellular viability percentage as low as approximately $50 \%$ (Figure 1C). These results were as expected since hPDCs are adherent cells. The binding of integrins on the surface of adherent cells to RGD leads to a cascade of signaling pathways that are important for their survival [39].

Table 1. Hydrogel nomenclature based on respective compositions.

\begin{tabular}{cccc}
\hline Nomenclature & $\%(w / v)$ PEG & Cross-linker & RGD $(\mu \mathbf{M})$ \\
\hline $2.5 \mathrm{R} 0$ & 2.5 & Regular & 0 \\
$2.5 \mathrm{RR}$ & 2.5 & Regular & 150 \\
$2.5 \mathrm{~F} 0$ & 2.5 & Fast & 0 \\
$2.5 \mathrm{FR}$ & 2.5 & Fast & 150 \\
$4 \mathrm{R} 0$ & 4 & Regular & 0 \\
$4 \mathrm{RR}$ & 4 & Regular & 150 \\
$4 \mathrm{~F} 0$ & 4 & Fast & 0 \\
$4 \mathrm{FR}$ & 4 & Fast & 150 \\
$6.5 \mathrm{R} 0$ & 6.5 & Regular & 0 \\
$6.5 \mathrm{RR}$ & 6.5 & Regular & 150 \\
$6.5 \mathrm{~F} 0$ & 6.5 & Fast & 0 \\
$6.5 \mathrm{FR}$ & 6.5 & Fast & 150 \\
$8 \mathrm{R} 0$ & 8 & Regular & 0 \\
$8 \mathrm{RR}$ & 8 & Regular & 150 \\
$8 \mathrm{~F} 0$ & 8 & Fast & 0 \\
$8 \mathrm{FR}$ & 8 & Fast & 150 \\
$6.5 \mathrm{RD}$ & 6.5 & Regular & 150 (scrambled RDG) \\
\hline
\end{tabular}

Further, although the calcein stain in the Live/Dead assay is not specific for the cytoskeleton, its distribution in the cytoplasm displays the cellular morphology. From these images (Figure 1), it is also clearly visible that the components of the hydrogels affected the shape of the hPDCs. At both time points, the cells in the hydrogels containing $150 \mu \mathrm{M}$ RGD $(2.5 \mathrm{RR}, 4 \mathrm{RR}, 4 \mathrm{FR}, 6.5 \mathrm{RR}, 6.5 \mathrm{FR}, 8 \mathrm{RR}$, and $8 \mathrm{FR}$ ) displayed a more spread morphology than the cells in the hydrogel formulations without $\mathrm{RGD}(2.5 \mathrm{R} 0,4 \mathrm{R} 0,4 \mathrm{~F} 0,6.5 \mathrm{R} 0,6.5 \mathrm{~F} 0,8 \mathrm{R} 0$, and 8F0). Moreover, the incorporation of a peptide with the scrambled sequence, RDG, did not lead to a spread morphology of the hPDCs, which further confirms the specificity of the peptide functionalization with RGD. Additionally, after only one week in culture, hPDCs in the hydrogels with the lowest concentration of PEG (2.5RR) already seemed to have a much more elongated shape than hPDCs in the 4RR, 6.5RR, and $8 R R$ hydrogels. One reason could be because the lower percentage of PEG used leads to lower hydrogel stiffness and the hPDCs sense a different mechanical rigidity, which in turn affects their shape. It has been well demonstrated that the amount of macromer used and the modulus of the construct are inversely related [11] and hence can affect the cellular response. Previous work conducted with similar PEG-VS hydrogels comprised of an adhesion ligand and cross-linked with MMP sensitive peptides or nondegradable dithiol cross-linkers have demonstrated a storage modulus $\left(G^{\prime}\right)$ ranging from 0.3 to $2 \mathrm{kPa}$ [17,40-42]. More specifically, 4-arm $20 \mathrm{kDa}$ PEG-VS hydrogels containing RGD and the same peptide sensitive cross-linkers as used herein showed an increase in $\mathrm{G}^{\prime}$ from approximately 0.5 to $1.5 \mathrm{kPa}$ as the macromer concentration increased from $3.5 \%$ to $5 \%(w / v)$, respectively [42]. Changing the peptide sequence in the cross-linker from GPQGIWGQ (R cross-linker) to VPMSMRGG (F cross-linker) did not change G' [42]. These values corresponded well with the storage modulus of $1.2 \pm 0.13 \mathrm{kPa}$ that our group had measured for $6.5 \%$ $(w / v)$ PEG-VS hydrogels that were cross-linked with dithiothreitol (DTT) [43]. Furthermore, it has also been shown that naïve stem cells such as MSCs, due to their plasticity, respond differently in lineage specification and their morphology dependent on the microenvironment of the matrix presented to them [44]. 


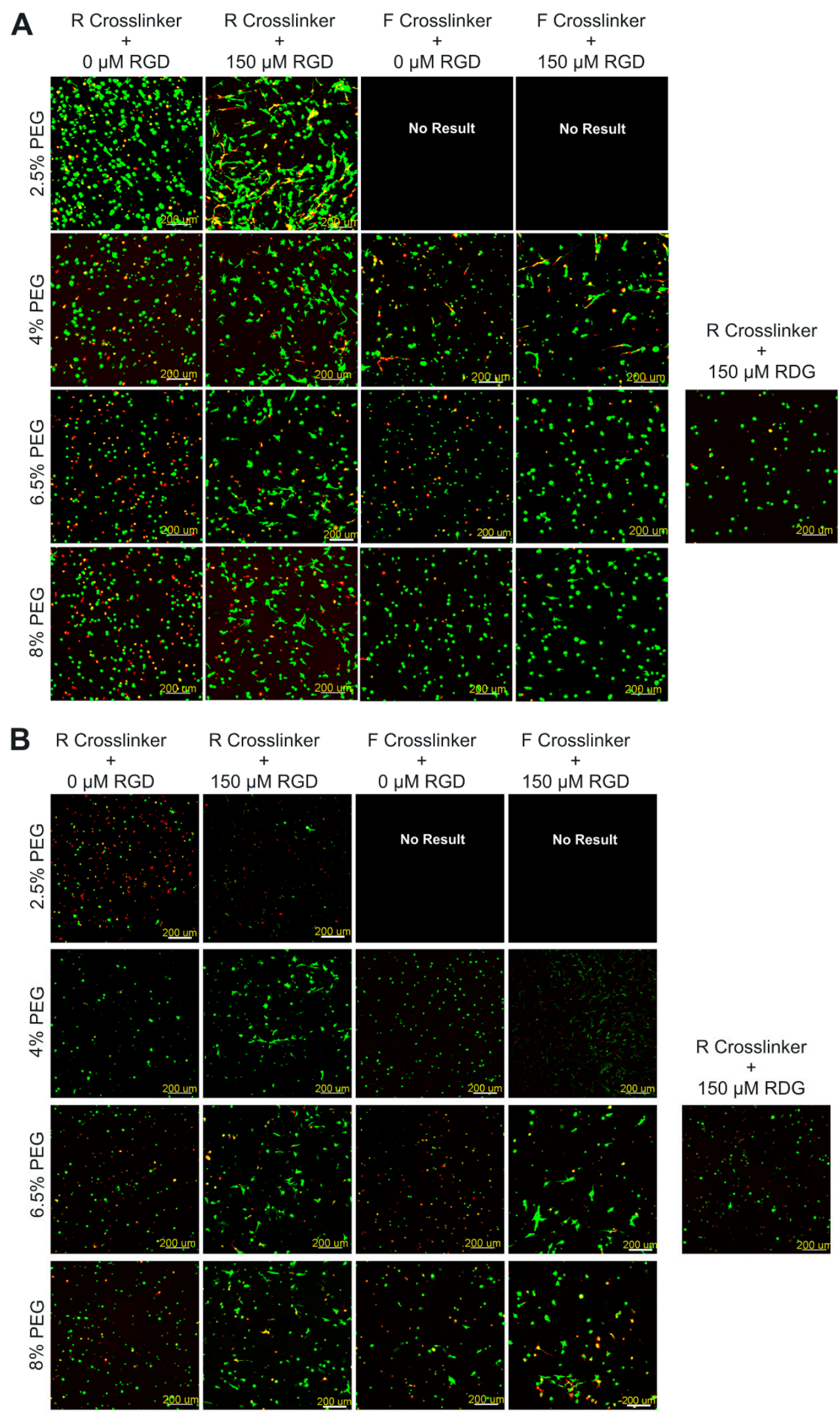

Figure 1. Cont. 


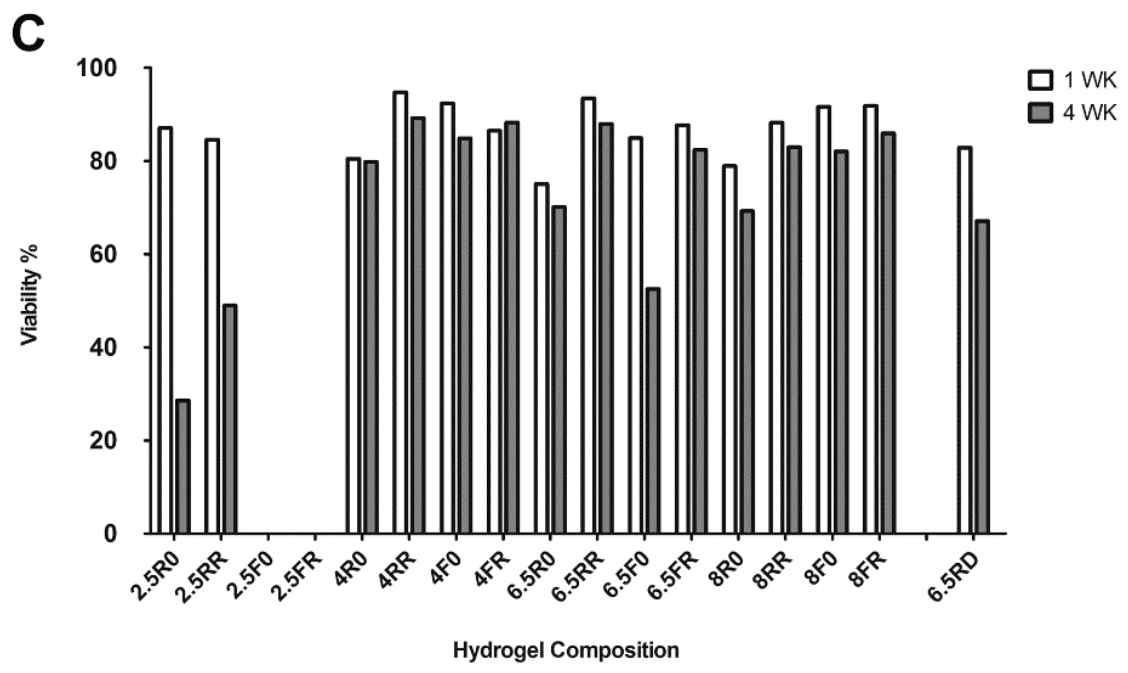

Figure 1. Human periosteum-derived cell (hPDC) viability within PEG-VS hydrogels made with different concentrations of macromer, different protease sensitive cross-linkers ( $R$ or F), and with or without the cell binding motif RGD or scrambled RDG after 1 week (A) and 4 weeks (B) of in vitro culture in GM. Representative images of Live/Dead staining with calcein AM (green, live cells) and ethidium homodimer-1 (red, dead cells). Confocal images are depicted as the maximum intensity of a $500 \mu \mathrm{m}$ z-stack that was acquired using a $10 \times$ objective (scale bars $=200 \mu \mathrm{m}$ ). (C) IMARIS software based quantification of viability percentages of cells encapsulated in polyethylene glycol (PEG) hydrogels ( $n=1$ independent sample; values depicted are the averages of two different measured areas within one sample).

Next, the DNA content of the various cell-laden hydrogels was analyzed after one week and four weeks of in vitro culture in GM (Figure 2). At one week, many of the hydrogels displayed a similar DNA content (insignificant $p$-values), with the exception of some compositions, namely 2.5R0, 2.5F0, 2.5FR, $4 \mathrm{~F} 0,4 \mathrm{FR}, 6.5 \mathrm{~F} 0$, and 6.5FR, showing a significantly reduced DNA content $(p<0.01)$. These compositions tended to be the ones with the faster degrading cross-linker and/or the lower concentrations of PEG. Nonetheless, after four weeks of culture, the DNA content in the RGD containing PEG hydrogels, specifically in the $4 \%$ and $6.5 \%(w / v)$ constructs, was significantly higher $(p<0.001)$ than not only the DNA content in their one week counterparts but also the DNA amounts in their counterparts without RGD at week $4(p<0.001)$. This indicates that time and hydrogel composition, especially the cell binding motif, play a crucial role in cell proliferation for hPDCs encapsulated within these PEG constructs. After one week, the $2.5 \%(w / v)$ PEG hydrogels, as mentioned before, were already swollen and weak, and hence their data should be interpreted with caution. On the other hand, although the $8 \%(w / v)$ PEG hydrogels demonstrated the capability to support hPDC viability over time, these hydrogels did not display any significant difference in their DNA content over time, except in the 8R0 hydrogels, where there was a significant drop in DNA content after four weeks $(p<0.001)$. This lack of cell proliferation in the $8 \%(w / v)$ PEG hydrogels could be due to the higher percentage of PEG leading to an increase in cross-linking density and stiffness and a decrease in mesh size. Previous work with PEG hydrogels has shown that doubling the concentration of PEG macromer led to an almost two-fold decrease in mesh size [9]. In addition, it has been previously demonstrated, with chondrocytes [45] as well as fibroblasts [46], that increasing mesh size supported cellular proliferation. Interestingly, many of the constructs without RGD displayed a significant drop in DNA content after four weeks $(p<0.001)$. The lack of RGD, combined with the slower degrading cross-linker, seemed to have a negative impact on hPDC proliferation, as the 4R0,6.5R0, and the $8 \mathrm{R} 0$ groups all demonstrated lower DNA content at four weeks compared to the DNA content of these groups at one week. The drop in DNA content of the hPDCs in the R0 hydrogels over time appears to be reproducible, as we have previously reported [26]. 


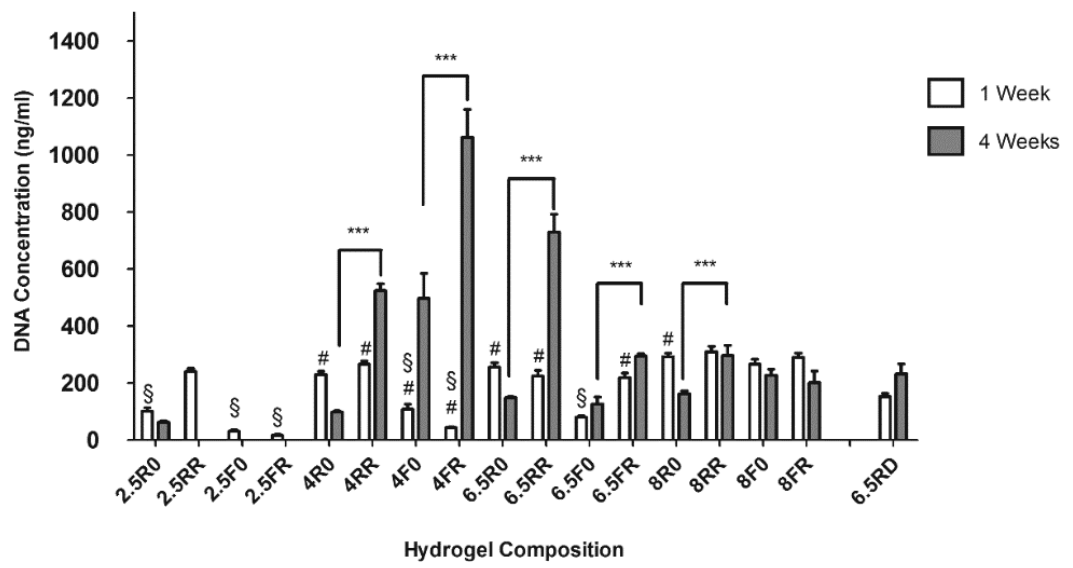

Figure 2. DNA content of cell-laden PEG hydrogels cultured in GM in vitro over time varying in the percentage of macromer, the cross-linker type, and the incorporation or lack of the cell binding motif, RGD, or scrambled peptide, RDG. Results are presented as mean $\pm \mathrm{SD}(n=3$; \# $p<0.001$ when comparing the hydrogel composition at 1 week to its 4 week counterpart; $\S p<0.01$ compared to 1 week DNA content of unmarked hydrogels; ${ }^{* * *} p<0.001$ when comparing otherwise similar hydrogels with and without RGD at 4 weeks).

2.1.2. GAG Production of hPDCs Encapsulated in PEG-VS Hydrogels Increases over Time when Cultured in Chondrogenic Differentiation Medium

In screening experiments such as this, it can quickly become infeasible to test all of the possible combinations of variables. To address this limitation, the design of experiments (DoE) approach is a powerful tool that allows the simultaneous evaluation of multiple variable/parameters in an efficient manner [47]. The proliferation data reported in the previous section were used with JMP software to create a fractional factorial design with three factors (PEG\%, RGD concentration, and cross-linker type) and two levels. Because the $2.5 \%$ and $8 \%(w / v)$ PEG constructs did not perform well in the proliferation experiment, they were excluded from the DoE analysis. Based on the 3-factor, multilevel DoE results, the $4 \mathrm{R} 0,4 \mathrm{FR}, 6.5 \mathrm{RR}$, and $6.5 \mathrm{~F} 0$ hydrogel compositions were selected to conduct a preliminary study of chondrogenic differentiation of hPDCs within the PEG hydrogels when cultured in 4C chondrogenic medium, which was measured by determining the glycosaminoglycan (GAG) production by the cells. The GAG/DNA content (Figure 3) of these groups demonstrated that the 6.5RR hydrogel formulation had a significantly higher GAG/DNA content than the other hydrogels after four weeks of culture. Based on the previous proliferation results and this preliminary chondrogenic differentiation study, it was concluded that the 6.5\% $(w / v)$ PEG hydrogels not only provided an environment to sustain hPDC proliferation but they also had the potential to support GAG production of the hPDCs when cultured in chondrogenic medium.

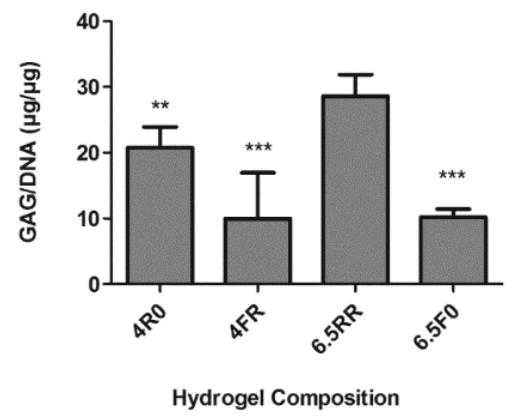

Figure 3. GAG/DNA content of selected PEG hydrogels after four weeks of in vitro chondrogenic stimulation in $4 \mathrm{C}$ chondrogenic medium. Hydrogel formulations were chosen based on previous proliferation data and design of experiments (DoE)-based software. Results depicted as mean \pm SD ( $n=3$; Student's $t$-Test ${ }^{* *} p<0.01,{ }^{* * *} p<0.001$ when compared to 6.5RR composition). 
As the 6.5RR group was one of the best performing hydrogel compositions in both of the prior experiments, a further investigation of the chondrogenic differentiation of hPDCs when encapsulated in $6.5 \%(w / v)$ PEG hydrogels and cultured in chondrogenic 4C medium was performed. The hydrogels varied only in the protease sensitive cross-linker used and the presence or absence of RGD. Cell-laden constructs were cultured in GM for $24 \mathrm{~h}$ and then subsequently switched to chondrogenic $4 \mathrm{C}$ medium and cultured for 1 and 4 weeks. When looking at the DNA content (Figure 4$)$ of these $6.5 \%(w / v)$ PEG hydrogels containing cells, at 0 weeks there was no difference in DNA content, implying that the hPDCs were initially encapsulated equally in the different hydrogels. At 1 week, there was no significant increase in the DNA content observed within these hydrogels that were cultured in $4 \mathrm{C}$ chondrogenic medium. However, at 4 weeks, the DNA content significantly dropped across all hydrogel formulations $(p<0.01)$. Moreover, in a similar trend as seen in the proliferation experiment (Figure 2), the 6.5R0 and 6.5F0 hydrogels displayed lower DNA content compared to their RGD containing counterparts, 6.5RR and 6.5FR, respectively. Additionally, the 6.5R0 construct displayed the lowest DNA content compared to the rest of the hydrogel formulations $(p<0.001)$. This drop in DNA content over the 4 weeks can possibly be attributed to the cell seeding density and/or the culture medium. The cells were encapsulated at a higher starting cell density than in the proliferation experiments reported in Section 2.1.1, and the cell-laden constructs were cultured in the 4C chondrogenic medium, which would favor differentiation over proliferation. Further, previous studies have reported that a higher cell density was not beneficial for proliferation since the cells tended to enter the quiescent phases of the cell cycle when cultured in conditions promoting differentiation [48].

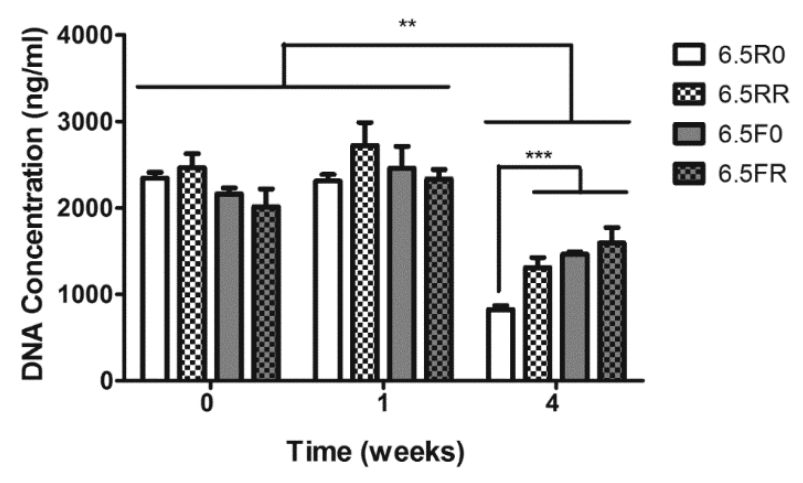

Figure 4. DNA quantification of encapsulated hPDCs within 6.5\% $(w / v)$ PEG hydrogels composed of two different types of cross-linkers (F or R) and functionalized with $150 \mu \mathrm{M}$ or $0 \mu \mathrm{M}$ RGD, when cultured in $4 \mathrm{C}$ chondrogenic medium. 6.5 $\mathrm{R} 0=\mathrm{R}$ cross-linker $+0 \mu \mathrm{M}$ RGD; $6.5 \mathrm{RR}=\mathrm{R}$ cross-linker +150 $\mu \mathrm{M}$ RGD; $6.5 \mathrm{~F} 0=\mathrm{F}$ cross-linker $+0 \mu \mathrm{M}$ RGD; 6.5FR $=\mathrm{F}$ cross-linker $+150 \mu \mathrm{M}$ RGD. Results depicted as mean \pm SD. (Two-way ANOVA; $n=3 ; * * * p<0.001 ; * * p<0.01$ ).

The DMMB GAG assay showed very low amounts of GAG/DNA being produced at 0 weeks (Figure 5). Additionally, there was no significant difference observed among the hydrogel compositions at this time point. After 1 week of chondrogenic stimulation via the $4 \mathrm{C}$ medium, the hPDCs in the hydrogels with the F cross-linker displayed a significant increase in GAG/DNA content $(p<0.05)$, but the hPDCs in the hydrogels with the R cross-linker did not experience any significant change. After 4 weeks of in vitro culture, all of the hydrogel formulations saw a significant increase in GAG production by the hPDCs compared to the hPDCs in the hydrogels at 0 and 1 weeks $(p<0.001)$. At the 4 week time point, the GAG production of the encapsulated hPDCs in the hydrogels cross-linked with the R cross-linker and containing RGD (6.5RR) was significantly higher than in the other hydrogel formulations. This trend correlates well with the results obtained from the DoE experiment, where the hPDCs in the 6.5RR hydrogel demonstrated the highest GAG/DNA production after 4 weeks of culture, although the absolute amount was higher in the previous results (Figure 3). This variance could arise due to the utilization of different biological replicates as well as the use of primary cells. Additionally, when comparing the GAG/DNA in this study to another study conducted with hPDC 
micromasses incorporating growth factor releasing gelatin microspheres [49], the GAG accumulation per cell was higher with the PEG constructs. This could indicate that the GAG is being retained in the PEG matrix, which would be beneficial when forming a cartilaginous tissue-engineered construct.

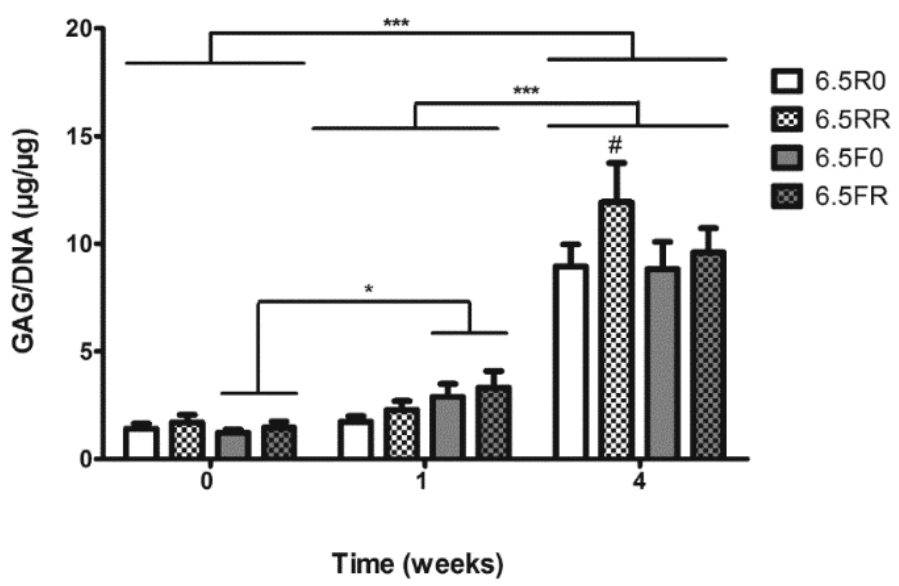

Figure 5. GAG/DNA content of encapsulated hPDCs within 6.5\% $(w / v)$ PEG hydrogels composed of two different types of cross-linkers (F or R) and functionalized with 150 or $0 \mu \mathrm{M}$ RGD, when cultured in $4 \mathrm{C}$ chondrogenic medium. $6.5 \mathrm{R} 0=\mathrm{R}$ cross-linker $+0 \mu \mathrm{M}$ RGD; $6.5 \mathrm{RR}=\mathrm{R}$ cross-linker $+150 \mu \mathrm{M}$ RGD; $6.5 \mathrm{~F} 0=$ F cross-linker $+0 \mu \mathrm{M}$ RGD; 6.5FR $=$ F cross-linker $+150 \mu \mathrm{M}$ RGD. Results are depicted as mean \pm SD. (Two-way ANOVA, $n=3$; ${ }^{* * *} p<0.001 ;{ }^{*} p<0.05 ; \# p<0.05$ when comparing to other hydrogel formulations at the particular time point).

Based on the results from both the proliferation and differentiation assays with hPDCs, it was concluded that the 6.5\% $(w / v)$ PEG hydrogels were well suited to carry out further experimental testing. Additionally, although the $2.5 \%(w / v)$ PEG hydrogels were deemed structurally unsound for the purpose of creating an in vitro cartilaginous construct, they could be an attractive choice as an injectable hydrogel for articular cartilage surface repair [50-52]. The low PEG macromer amount used could make it injectable via a syringe after hydrogel formation, as these PEG constructs with low macromer concentrations have been shown to possess lower moduli and lower stiffness [53] and thus could be deformed when passing through a syringe.

\subsection{Screening Using ATDC5 Cells Encapsulated in PEG Hydrogels and Cultured in Chondrogenic Differentiation Medium}

2.2.1. Extent of ATDC5 Viability and Proliferation when Encapsulated within PEG Hydrogels and Cultured in Chondrogenic Differentiation Medium

As aforementioned, ATDC5 is a valuable cell line to test in vitro chondrogenesis. In this study, the use of a cell line instead of primary cells allowed us to perform additional assays, such as histology staining, to characterize the behavior of the cells within the protease sensitive PEG hydrogels when cultured in chondrogenic differentiation medium. Further, they allowed us to validate if the most promising hydrogel compositions identified in Section 2.1 show reproducible chondrogenesis with a different cell source. First, in the 6.5\% ( $w / v)$ PEG hydrogels, the ATDC5 cells displayed a viability percentage of approximately $75 \%$ or higher at 0 weeks (Figure $6 \mathrm{~A}$ ). Moreover, as they continued to be cultured over 4 weeks in the $4 \mathrm{C}$ chondrogenic differentiation medium, they demonstrated no drop in viability for any of the different hydrogel constructs. This can be qualitatively observed in the images of the Live/Dead staining (Figure 6B), as all of the panels display a majority of green (live) cells as opposed to red (dead) cells. The viability results herein are similar to when ATDC5 cells were encapsulated within hyaluronic acid/PEG hydrogels formed via click chemistry, where the cells displayed a high viability after 7 days of culture in a maintenance medium composed of DMEM and F12 [37]. 
A

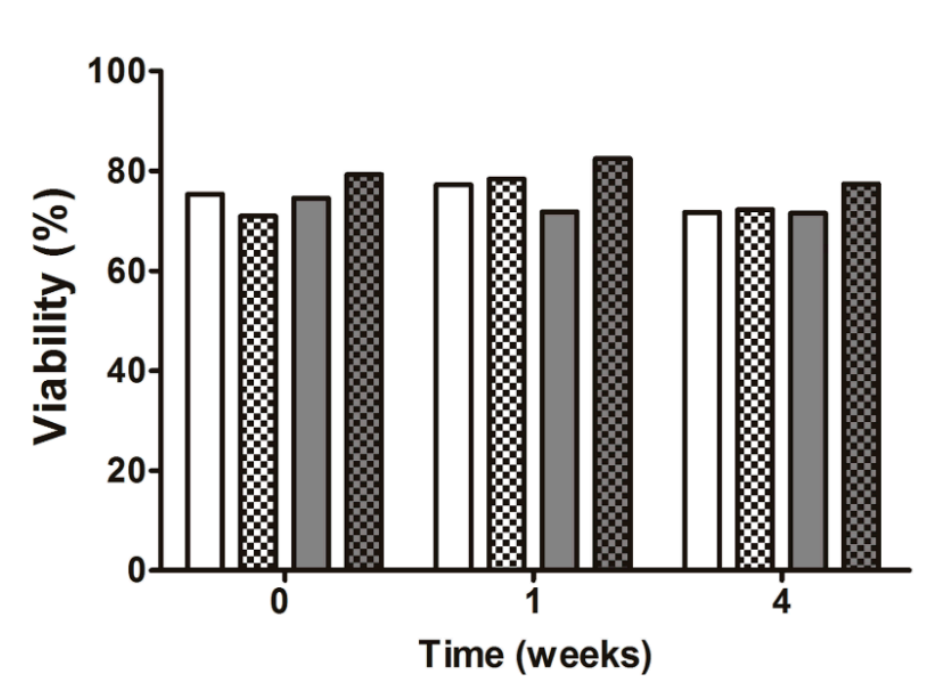

6.5F0

6.5FR
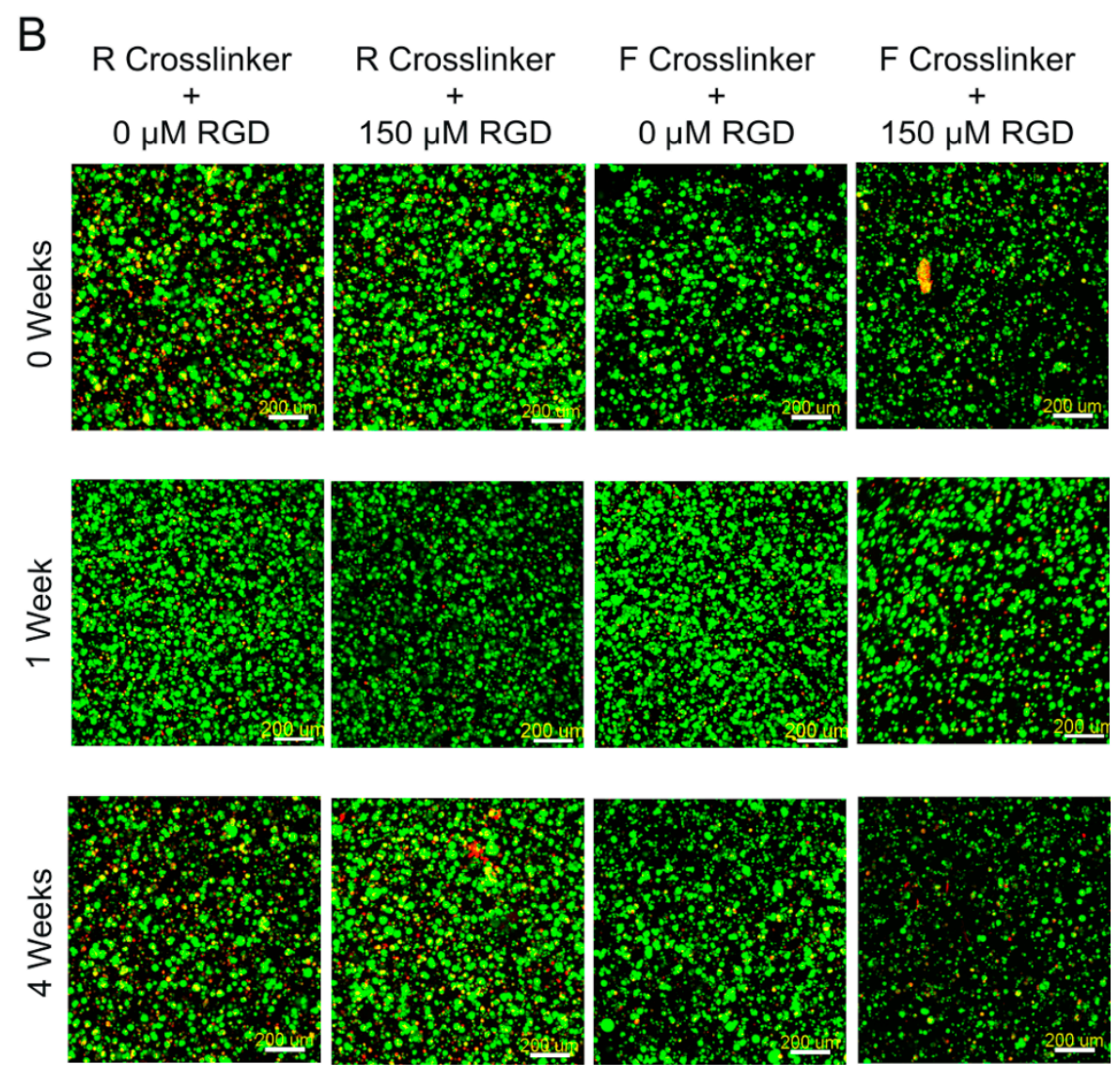

Figure 6. ATDC viability within protease sensitive 6.5\% $(w / v)$ PEG-VS hydrogels, with different cross-linkers (F or R) as well as with and without RGD, cultured over time. Constructs were examined at 0 weeks ( $24 \mathrm{~h}$ in $\mathrm{MM}$ ) and 1 and 4 weeks in the $4 \mathrm{C}$ chondrogenic differentiation medium. 6.5R0 $=\mathrm{R}$ cross-linker $+0 \mu \mathrm{M}$ RGD; 6.5RR $=\mathrm{R}$ cross-linker $+150 \mu \mathrm{M}$ RGD; 6.5F0 = F cross-linker + $0 \mu \mathrm{M}$ RGD; 6.5FR = F cross-linker $+150 \mu \mathrm{M}$ RGD. (A) IMARIS software based quantification of viability percentages of ATDC5 cells encapsulated in PEG hydrogels $(n=1$; values depicted are the averages of two different measured areas within one sample). (B) Representative confocal images of Live/Dead staining shown as the maximum intensity of a $500 \mu \mathrm{m}$ z-stack where live cells are green and dead cells are red (scale bar $=200 \mu \mathrm{m})$. 
Following the evaluation of the viability of ATDC5 cells, the proliferation of these cells within these constructs, when cultured in $4 \mathrm{C}$ medium, was determined (Figure 7). At the 0 week time point, there was no significant difference in the DNA content of the different constructs. As with the results for hPDCs in Section 2.1.2, this lack in difference in DNA content demonstrates equal initial cell amounts inside the hydrogels. At 1 week, the hydrogels with the regular degrading cross-linker (6.5RR, 6.5R0) did not have a significant difference in DNA content compared to their respective counterparts at 0 weeks. However, the cells within the 6.5FR hydrogels displayed a significant increase in their DNA content $(p<0.001)$ when compared to cells in the same hydrogel formulation at 0 weeks, which was an indication that the cells were proliferating in this specific hydrogel composition. Furthermore, at this time point, the cells displayed significantly more DNA content in the 6.5FR hydrogels compared to the $6.5 \mathrm{~F} 0$ construct $(p<0.01)$. Similar to 1 week, at 4 weeks the cells within both of the hydrogels with the $\mathrm{R}$ cross-linker did not demonstrate a change in DNA content, thus maintaining their cellular numbers over the entire culture time. After witnessing a significant increase in the DNA content of the 6.5FR group after 1 week of in vitro culture, the ATDC 5 cells demonstrated a significant drop in DNA levels $(p<0.001)$. However, this drop was only down to the levels at 0 weeks, and no difference was observed between 0 and 4 weeks. Lastly, the 6.5F0 hydrogel displayed a significant drop $(p<0.001)$ in ATDC5 DNA content when compared to its cell-laden counterparts at 0 and 1 week.

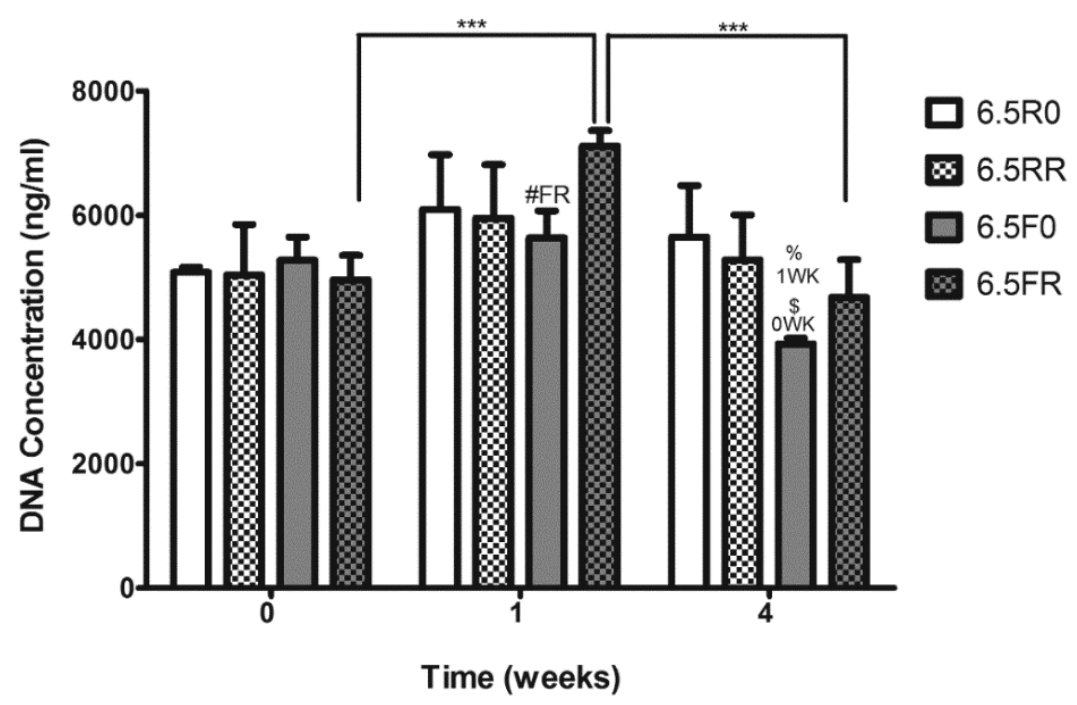

Figure 7. DNA quantification of ATDC5 cells encapsulated inside 6.5\% (w/v) PEG hydrogels varying in the cross-linker type ( $F$ or R) and RGD content, and cultured over time in $4 \mathrm{C}$ chondrogenic medium. 6.5R0 $=\mathrm{R}$ cross-linker $+0 \mu \mathrm{M}$ RGD; 6.5RR $=\mathrm{R}$ cross-linker $+150 \mu \mathrm{M}$ RGD; 6.5F0 = F cross-linker + $0 \mu \mathrm{M}$ RGD; 6.5FR = F cross-linker + $150 \mu \mathrm{M}$ RGD. Results depicted as mean \pm SD (Two-way ANOVA; $n=3$; \#FR $p<0.01$ compared to FR formulation at 1 week; $\% 1 W K p<0.001$ compared to the hydrogel at 1 week with the same composition. $\$ 0 \mathrm{WK} p<0.001$ compared to the hydrogel at 0 week with the same composition; $\left.{ }^{* * *} p<0.001\right)$.

2.2.2. GAG and Collagen Production by ATDC5 Cells Encapsulated in Protease Degradable PEG-VS Hydrogels

To examine the in vitro chondrogenic capability of ATDC5 cells in PEG hydrogels, a DMMB GAG assay and histology were used to quantitatively and qualitatively demonstrate the extent of chondrogenic differentiation taking place within the hydrogel constructs. The quantitative GAG assay displayed a significant increase in the production of GAG by ATDC 5 cells within these hydrogels (Figure 8). At 0 weeks, before being switched to chondrogenic medium, the GAG production by the encapsulated cells was very low among all the hydrogel formulations. After one week of in vitro culture in the 4C medium, the RGD containing hydrogels, 6.5RR and 6.5FR, demonstrated a significant increase $(p<0.05)$ in GAG production by the encapsulated ATDC5 cells, compared to the cellular 
GAG production in their respective hydrogel formulations at 0 weeks. 6.5FR is the same hydrogel formulation that displayed a significant DNA increase after one week of culture. After four weeks of in vitro chondrogenic stimulation, all of the ATDC5 laden hydrogels displayed a significant increase in GAG/DNA content not only compared to one week $(p<0.05)$ but also compared to 0 weeks $(p<0.001)$. However, at 4 weeks, there was no difference among the various hydrogel formulations.

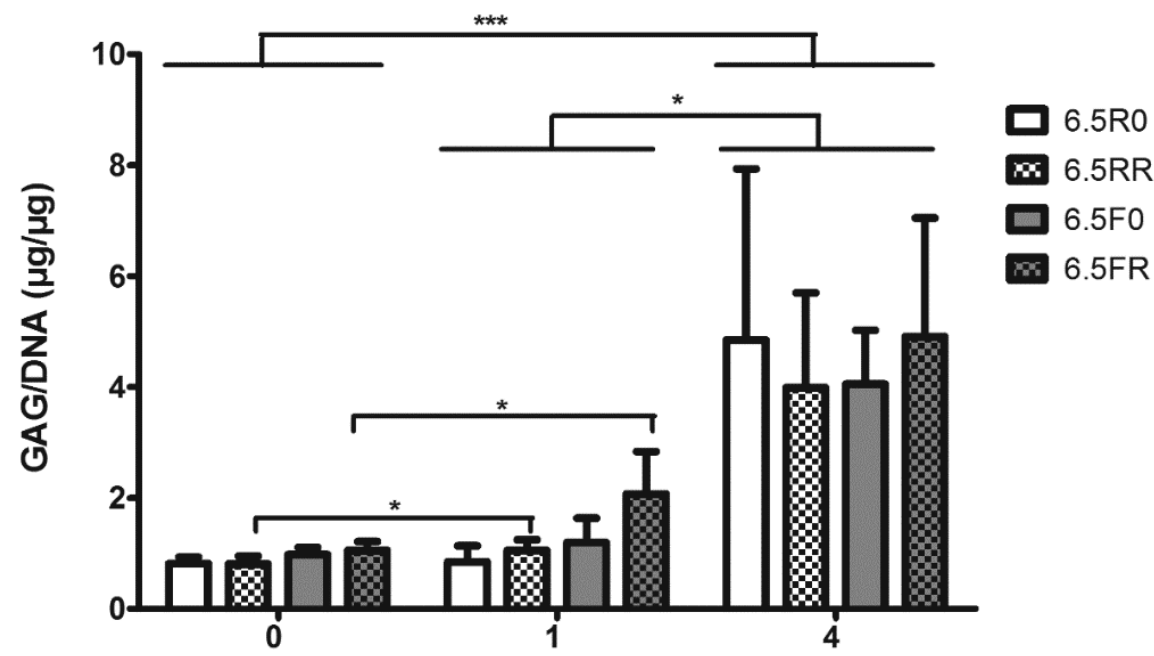

Time (weeks)

Figure 8. GAG/DNA content of ATDC5 cells encapsulated inside $6.5(w / v)$ PEG hydrogels varying in the cross-linker type (F or R) and RGD content $(0$ or $150 \mu \mathrm{M})$, and cultured over time in $4 \mathrm{C}$ chondrogenic medium. $6.5 \mathrm{R} 0=\mathrm{R}$ cross-linker $+0 \mu \mathrm{M}$ RGD $6.5 \mathrm{RR}=\mathrm{R}$ cross-linker $+150 \mu \mathrm{M} \mathrm{RGD} ; 6.5 \mathrm{~F} 0=\mathrm{F}$ cross-linker + $0 \mu \mathrm{M}$ RGD; 6.5FR $=$ F cross-linker $+150 \mu \mathrm{M}$ RGD. Results depicted as mean $\pm \mathrm{SD}$ (Two-way ANOVA $\left.n=3 ;^{*} p<0.05 ;{ }^{* * *} p<0.001\right)$.

Lastly, when looking at the safranin-O (Figure 9A) and picrosirius red (Figure 9B) stains of the sectioned cell-laden constructs, it can be seen that in vitro culture in the chondrogenic medium had a positive effect on the cartilaginous matrix production of ATDC 5 cells encapsulated in the 3D PEG hydrogels. More specifically, safranin-O stains for highly-sulfated GAGs [54], and thus the images should qualitatively correspond with the quantitative GAG assay. At 0 weeks, there was no indication of positive stain within any of the constructs. Although the image of F0 might seem to be depicting positive staining, it is due to a condensation artifact caused during the mounting process. At one week, both of the hydrogels with the R cross-linker displayed a higher amount of positive staining, depicted by the blue arrows, than the hydrogels formed with the F cross-linker. Similarly at four weeks, there were continued signs of positive safranin-O staining, especially in the hydrogel with the $\mathrm{R}$ cross-linker and RGD (6.5RR). The picrosirius red staining displayed similar trends as the safranin-O staining. Picrosirius red stains collagen, and due to its birefringence, the stained collagen will show up orange in color when imaged with polarized light $[55,56]$. For instance, at 0 weeks, none of the hydrogels depicted any positive collagen staining. At one week, some of the hydrogels, such as the RGD containing hydrogel with the regular degrading cross-linker (6.5RR), demonstrated a faint sign of positive orange spots. After four weeks, cells in all of the hydrogels displayed positive collagen staining, depicted by the orange spots spread out within the hydrogel. 
A
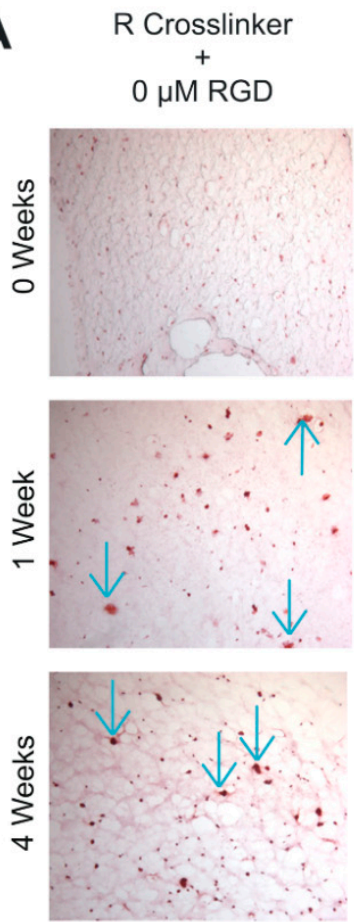

B
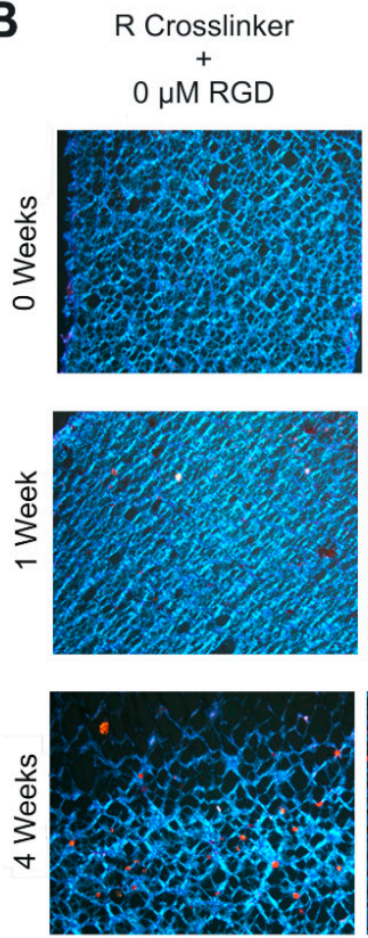

R Crosslinker $+$ $150 \mu \mathrm{M} R \mathrm{RGD}$
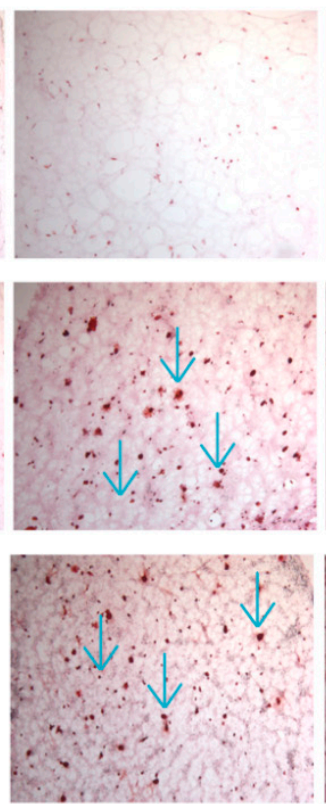

R Crosslinker $150 \mu \mathrm{M}$ RGD
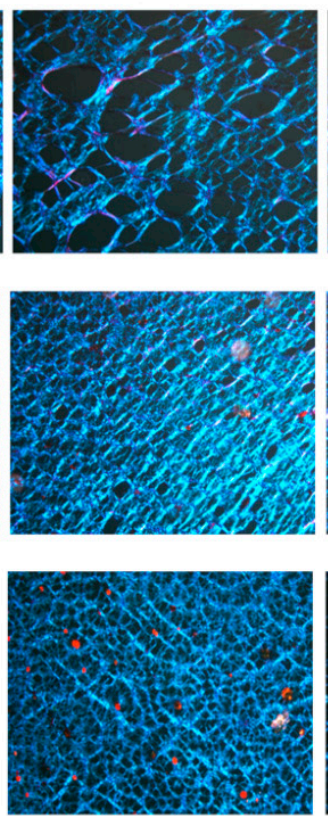
F Crosslinker
$+$
$0 \mu \mathrm{M}$ RGD
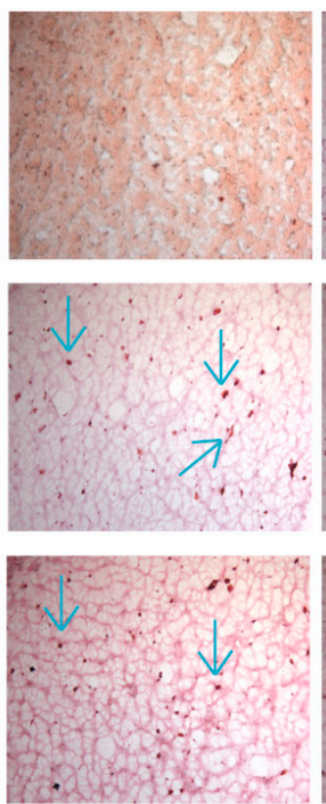

F Crosslinker

$0 \mu \mathrm{M} R \mathrm{RGD}$
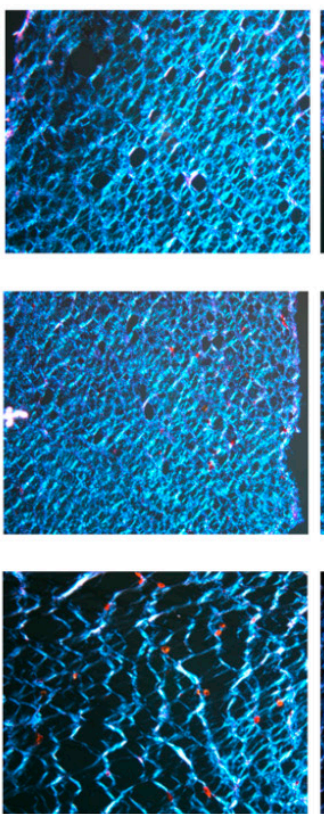

F Crosslinker $+$ $150 \mu \mathrm{M}$ RGD
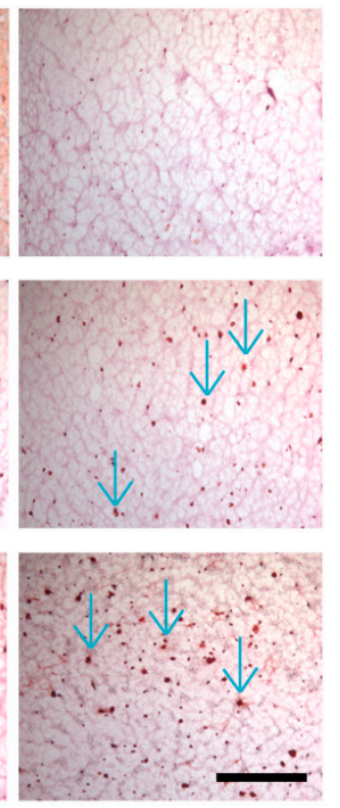

F Crosslinker

$150 \mu \mathrm{M}$ RGD
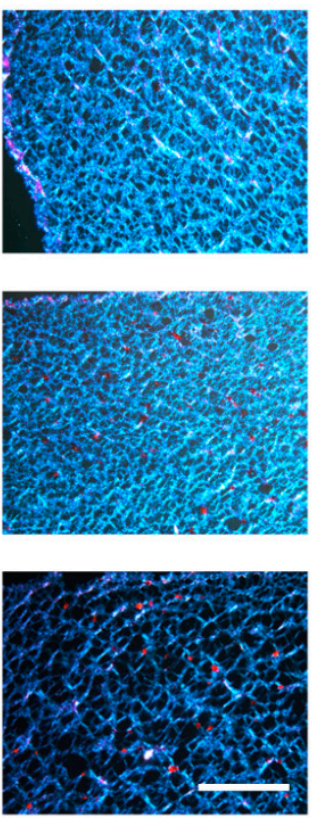

Figure 9. Representative images of histological staining of ATDC5 cells encapsulated in $6.5 \%(w / v)$ PEG hydrogels. (A) Brightfield images of safranin-O stained sections for visualizing GAG deposition. Positive staining is demarcated via blue arrows. (B) Polarized light images of picrosirius red stained sections demonstrating collagen production. Collagen is displayed orange under polarized light. All images taken with $10 \times$ objective on a Leica microscope. (Scale bar $=100 \mu \mathrm{m})$.

Both sets of the stained histological sections depicted a more pericellular, localized staining, as opposed to being distributed throughout the hydrogel. This could be due to the properties of the hydrogels, such as mesh size, leading to the retention of the newly synthesized ECM components in a 
more local spot and preventing them from diffusing throughout the hydrogels. A similar phenomenon was observed with ATDC5 cells encapsulated in fibrin hydrogels (unpublished data). Additionally, when porcine vocal fold fibroblasts where encapsulated within unmodified PEG diacrylate hydrogels, a similar localized ECM deposition was observed, which was attributed to the unmodified nature of the hydrogel [46].

\section{Materials and Methods}

\section{1. hPDC Cell Culture}

Cells were harvested and isolated from similarly aged donors $(n=4$; two male and two female donors, average age $13.7 \pm 2.5$ years) and combined together with respect to their in vitro growth kinetics and in vivo bone-forming capacity, as previously described [57]. Thawed hPDCs were seeded at an initial density of 5000 cells $/ \mathrm{cm}^{2}$ in T-150 tissue flasks and cultured in growth medium (GM) composed of high-glucose Dulbecco's Modified Eagle's Medium (DMEM Glutamax; Invitrogen, Merelbeke, Belgium), supplemented with 10\% fetal bovine serum (FBS; BioWhittaker, Walkersville, MD, USA), $1 \%$ antibiotic-antimycotic solution (100 units $/ \mathrm{mL}$ penicillin; $100 \mu \mathrm{g} / \mathrm{mL}$ streptomycin; $0.25 \mu \mathrm{g} / \mathrm{mL}$ amphoterecin B; Invitrogen), and $1 \%$ sodium pyruvate (1 mM; Invitrogen). Cells at passage 8 were trypsin-released and encapsulated within the PEG hydrogels. Informed consent was obtained from each of the donors, and all procedures involving primary cells were approved by the Medical Ethics Committee UZ KU Leuven (study reference S53717, approved on 8 October 2012).

\subsection{ATDC5 Cell Culture}

ATDC5 cells (Riken Cell Bank, Tsukuba, Japan) were grown in a maintenance medium (MM) composed of Dulbecco's Modified Eagle Medium/Ham's Nutrient Mixture F12 (DMEM/F12) (1:1; Invitrogen), $5 \%$ fetal bovine serum (FBS; BioWhittaker), $1 \%$ antibiotic-antimycotic solution, $10 \mathrm{mg} / \mathrm{mL}$ human transferrin (Sigma, Bornem, Belgium), and $30 \mathrm{nM}$ sodium selenite (Sigma), as previously described $[33,36]$. Medium was refreshed every 2 to 3 days, and the cells were passaged prior to becoming confluent.

\subsection{Hydrogel Preparation and Cell Encapsulation}

Michael-Type addition-based PEG-VS hydrogels-containing cells were made via the protocol previously described [7]. Briefly, for the initial in vitro proliferation and viability screening with hPDCs, 20 kDa 4-arm PEG-VS (JenKem, Plano, TX, USA) was dissolved in 0.3 M HEPES buffer, pH 8, for final concentrations of $2.5 \%, 4 \%, 6.5 \%$, or $8 \%(w / v)$. For the DoE based experiments, only 4 and $6.5 \%$ $(w / v)$ were utilized. For the in vitro chondrogenic screening studies with ATDC5 cells and hPDCs, a final concentration of only $6.5 \%(w / v)$ was used. Subsequently, $150 \mu \mathrm{M}$ (final concentration in hydrogel) of the adhesion binding peptide containing a free thiol (Ac-GCGYGRGDSPG- $\mathrm{NH}_{2}$ ) was functionalized onto the PEG-VS macromer. For hydrogels without RGD $(0 \mu \mathrm{M})$, an equal volume of buffer was added. Following an incubation period, a trypsin released cell suspension of either hPDCs for proliferation studies $\left(1 \times 10^{6}\right.$ cells $/ \mathrm{ml}$ final concentration) or hPDCs and ATDC 5 cells for differentiation studies $\left(10 \times 10^{6}\right.$ cells $/ \mathrm{ml}$ final concentration) was mixed with two different dithiol, MMP-sensitive cross-linkers with different degradation rates, referred to as either $\mathrm{R}$ or $\mathrm{F}$ (Ac-GCREGPQGIWGQERCG-NH ${ }_{2}$ or Ac-GCRDVPMSMRGGDRCG-NH ${ }_{2}$, respectively [19]). Finally, the PEG-VS solutions, with or without RGD incorporation, were reacted with their respective cross-linker and cell suspensions. Additionally, as a control for the incorporation of the cell binding sequence, a scrambled RDG sequence was alternatively incorporated into some of the hydrogels. The hydrogel nomenclature indicates the concentration of PEG, type of cross-linker, and presence or absence of RGD (Table 1). Twenty microliter drops of the hydrogel precursor solutions were sandwiched between hydrophobic SigmaCote (Sigma) treated glass slides with $1 \mathrm{~mm}$ spacers and incubated at $37^{\circ} \mathrm{C}$ for $30 \mathrm{~min}$ to allow full cross-linking to occur. The resulting cell-laden hydrogel 
disks of approximately $8 \mathrm{~mm}$ in diameter were cultured in well plates with the respective media formulations. Peptides were sourced from Biomatik (Cambridge, ON, Canada) or PeptideSynthetics (Fareham, UK) or were prepared by solid phase peptide synthesis and purified via HPLC-MS.

\subsection{Culture Conditions}

For the proliferation studies with hPDCs, cell-laden hydrogels were cultured in well plates in regular GM. Samples were analyzed at 1 week and 4 weeks of culture. For the differentiation studies, the cell-laden constructs were placed in well plates with GM and MM for hPDCs and ATDC5s, respectively. After $24 \mathrm{~h}$, all the cell-laden constructs were switched to $4 \mathrm{C}$ chondrogenic differentiation medium (DMEM/F12 (Invitrogen) with $5 \%$ FBS, $10 \mathrm{ng} / \mathrm{ml}$ transforming growth factor- $\beta 1$ (PeproTech), 1X Insulin Transferrin Selenium + premix (ITS+; BD Biosciences, Erembodegem, Belgium), $100 \mu \mathrm{g} / \mathrm{mL}$ ascorbic acid, $100 \mathrm{nM}$ dexamethasone, and 1\% antibiotic-antimycotic) [33,35], which was replenished every 2 to 3 days. Samples were analyzed prior to switching to chondrogenic differentiation medium (defined as 0 weeks) and after 1 and 4 weeks in the chondrogenic differentiation medium.

\subsection{Cell Viability Assay}

The capability of the different hydrogel compositions to support cellular viability was analyzed using a Live/Dead kit (Invitrogen). After a wash with phosphate buffered saline (PBS; Gibco, Merelbeke, Belgium) for 5 to $10 \mathrm{~min}$, a staining solution of calcein AM and ethidium homodimer-1 (ETH-1) in PBS was added to the wells and incubated for 30 to $45 \mathrm{~min}$ at $37{ }^{\circ} \mathrm{C}$. Following the incubation, the constructs were further washed in PBS. The stained samples were imaged using a FluoView confocal microscope with $10 \times$ objective at step size of $10 \mu \mathrm{m}$ and a total thickness of $500 \mu \mathrm{m}$ (Olympus, Berchem, Belgium). The 3D view in the Imaris software 7.2.3 (Bitplane, Zurich, Switzerland) was utilized to quantify the images. The images are represented as the maximum intensity of the z-stack in all figures.

\subsection{PicoGreen/Quant-iT DNA Quantification}

A PicoGreen/Quant-iT kit (Invitrogen) was used to investigate the effect of the various hydrogel formulations on cellular proliferation. The DNA content of three hydrogels per condition and per time point was calculated. The hydrogels were first digested in a buffer composed of $0.5 \mathrm{mg} / \mathrm{mL}$ Proteinase-K (Sigma) and 0.1\% Triton X-100 in 5 mM EDTA in PBS, pH 7.1 (PBE) overnight at $60{ }^{\circ} \mathrm{C}$. Following the complete degradation of the constructs, a working solution of the provided reagent was prepared according to the manufacturer's instructions. The samples were read using the Qubit Fluorometer (Invitrogen), and the DNA concentration was calculated based on the equation provided by the manufacturer.

\subsection{Design of Experiments Analysis}

A 'Design of Experiments' (DoE) analysis was utilized to help determine the influence that the different variables of the hydrogel composition had on the proliferation of the cells. A three factor (PEG \% $(w / v)$, MMP sensitive peptide cross-linker, and RGD concentration $(\mu \mathrm{M})$ ), two-level fractional factorial design was used. The $4 \%$ and $6.5 \%(w / v)$ PEG concentrations were selected based on the initial proliferation screening criteria. The two cross-linkers with different degradation rates (R vs. F) were identified based on previous work [19]. The RGD concentrations were as previously described, 0 vs. $150 \mu \mathrm{M}$. A JMP software package 10 (SAS, Marlow, UK) was used to select a limited number of hydrogel formulations to evaluate further in the preliminary chondrogenic differentiation experiment.

\subsection{DMMB GAG Assay}

To quantify the extent of the chondrogenic differentiation taking place within the cell-laden hydrogels, a dimethylmethylene blue (DMMB) GAG assay was used. The samples digested by proteinase $\mathrm{K}$ that were 
used in the DNA assay were also used for the DMMB assay to quantify the amount of GAG produced, which was then normalized to the DNA content. Briefly, 1,9-dimethylmethylene blue chloride (Sigma) was dissolved in ethanol overnight and then added to reach a final concentration of $46 \mu \mathrm{M} \mathrm{DMMB}$ in a $0.04 \mathrm{M} \mathrm{NaCl} /$ glycine solution, $\mathrm{pH}$ 3. The filtered solution was measured to have 0.314 OD at $525 \mathrm{~nm}$. Then, a serial dilution of chondroitin sulfate (CS; Sigma), ranging from 0 to $100 \mu \mathrm{g} / \mathrm{mL}$, was prepared using PBE. Finally, $270 \mu \mathrm{L}$ of the DMMB dye solution was combined with $30 \mu \mathrm{L}$ of the samples or the CS standards in a 96-well plate, and the absorbance was read at $570 \mathrm{~nm}$. The GAG concentration was calculated using the CS standard curve and subsequently divided by its corresponding DNA content to calculate GAG/DNA ( $\mu \mathrm{g} / \mu \mathrm{g})$.

\subsection{Histology}

For the differentiation screening, hydrogels were first washed with two consecutive 10 min washes of fresh PBS. Following the PBS washes, the cell-laden constructs were placed in cassette sample holders and submerged in optimal cutting temperature (OCT) solution for $30 \mathrm{~min}$. Subsequently, samples were snap frozen in liquid nitrogen, and $10-\mu \mathrm{m}$ slices were sectioned on a cryostat machine and stained for safranin-O and picrosirius red to analyze the GAG production and collagen production, respectively. Briefly, for safranin-O staining, frozen sections were first let to air dry, rehydrated, and then immersed in $0.25 \%$ safranin-O solution for $7 \mathrm{~min}$. Sections were then rinsed with water, fixed in methanol, dehydrated via graded ethanol, and mounted. For picrosirius red staining, air dried sections were rehydrated and placed in a picrosirius red solution (Sigma) for $1 \mathrm{~h}$ at room temperature. Next, stained sections were washed twice in fresh acidified water, fixed in methanol, dehydrated in graded ethanol, and finally, mounted. Brightfield images of safranin-O and polarized images of picrosirius red stained sections were taken using a DMR microscope (Leica Microsystems, Diegem, Belgium). For all sections, images were taken using a $10 \times$ objective.

\subsection{Statistical Analysis}

All quantitative outcomes $(n=3)$ are depicted as mean \pm standard deviation. For the initial DNA quantification screening, the statistical analysis was done using a basic Student's $t$-test to evaluate the effect of time among the hydrogels with similar compositions. An additional Student's $t$-test was done between the hydrogels that were otherwise similar but differed in the RGD concentrations. A basic Student's $t$-test was also conducted to compare the GAG production of the selected hydrogel formulations from the DoE. A two-way ANOVA was used for the subsequent DNA and GAG assays with hydrogel composition and time as the variables. Significant results and the respective $p$-values are indicated within each figure caption.

\section{Conclusions}

Combining the results of the ATDC 5 cells with those of the hPDCs, the work herein has displayed that varying the composition of the hydrogels has different effects on the cells. From the initial proliferation study, it was evident that the $2.5 \%$ and $8 \%(w / v)$ constructs negatively affected cell survival, while the $4 \%$ and $6.5 \%(w / v)$ hydrogels helped cells proliferate over time, especially in the RGD containing compositions. We utilized the proliferation results as input criteria for the DoE to help further screen the different combinations. The DoE based chondrogenic differentiation screening helped to take one step closer to determining an ideal composition of the hydrogel constructs. In the DoE-related chondrogenic screening, the hydrogel made of $6.5 \%(w / v)$ macromer functionalized with RGD and the R cross-linker displayed the highest GAG/DNA after four weeks of in vitro culture. This was the same construct that also displayed one of the highest levels of DNA content in the proliferation experiment. Following the hPDC screening, the $6.5 \%(w / v)$ hydrogels were used to encapsulate ATDC5 cells, which were analyzed after culture in chondrogenic medium via the DMMB assay as well as qualitatively via safranin-O and picrosirius red histology. Taken together, via the screening studies, the cell-laden constructs prepared with 6.5\% $(w / v)$ PEG-VS macromer and cross-linked with the protease 
sensitive peptide cross-linkers can support both the proliferation and chondrogenic differentiation of these cell types. Therefore, these formulations would be interesting to further explore with different chondrogenic stimulation media to evaluate their effects on encapsulated cells. Furthermore, since ATDC 5 cells have been shown to be the gold standard for in vitro chondrogenic simulation and testing, future work combining them with optimized hydrogels could be applied in research areas such as cartilage tissue on a chip [58].

Author Contributions: Conceptualization, J.P. and A.K.K.; Methodology, A.K.K. and J.P.; Formal Analysis, A.K.K.; Investigation, A.K.K.; Resources, F.P.L. and J.P.; Writing-Original Draft Preparation, A.K.K.; Writing - Review and Editing, J.P. and F.P.L.; Supervision, J.P.; Project Administration, F.P.L. and J.P.; Funding Acquisition, F.P.L. and J.P.

Funding: This research was funded by the Onderzoeksraad, KU Leuven, grant number IDO/13/016; the Fonds Wetenschappelijk Onderzoek (FWO), grant number G.0982.11N; and the European Research Council under the European Union's Seventh Framework Programme (FP7/2007-2013), ERC grant agreement number 294191, EU-FP7-REJOIND-RTD.

Acknowledgments: We thank Carla Geeroms and Kathleen Bosmans for their help with cell culture. Confocal imaging was performed in the Molecular Imaging and Photonics Lab, led by Johan Hofkens and Maarten Roeffaers, at KU Leuven.

Conflicts of Interest: The authors declare no conflicts of interest.

\section{Abbreviations}

$\begin{array}{ll}\text { ACI } & \text { Autologous chondrocyte implantation } \\ \text { CS } & \text { Chondroitin sulfate } \\ \text { DMEM } & \text { Dulbecco's modified Eagle's medium } \\ \text { DMMB } & \text { Dimethylmethylene blue } \\ \text { DoE } & \text { Design of experiments } \\ \text { DTT } & \text { Dithiothreitol } \\ \text { ECM } & \text { Extracellular matrix } \\ \text { ETH-1 } & \text { Ethidium homodimer-1 } \\ \text { FBS } & \text { Fetal bovine serum } \\ \text { GAG } & \text { Glycosaminoglycan } \\ \text { GM } & \text { Growth medium } \\ \text { hPDC } & \text { Human periosteum-derived cell } \\ \text { Ihh } & \text { Indian hedgehog } \\ \text { ITS+ } & \text { Insulin transferrin selenium }+ \\ k_{\text {cat }} & \text { Catalytic rate constant } \\ K_{\mathrm{M}} & \text { Michaelis constant } \\ \text { MM } & \text { Maintenance medium } \\ \text { MMP } & \text { Matrix metalloproteinase } \\ \text { MSC } & \text { Mesenchymal stem cell } \\ M_{\mathrm{W}} & \text { Molecular weight } \\ \text { OCT } & \text { Optimal cutting temperature } \\ \text { PAMPS } & \text { Poly(2-acrylamido-2-methyl-1-propanesulfonic acid) } \\ \text { PBE } & \text { Phosphate buffered EDTA } \\ \text { PBS } & \text { Phosphate buffered saline } \\ \text { PDMAAm } & \text { Poly(dimethylacrylamide) } \\ \text { PEG } & \text { Polyethylene glycol } \\ \text { PEG-DM } & \text { Polyethylene glyocol di-methacrylate } \\ \text { PEG-VS } & \text { Vinyl sulfone end-functionalized polyethylene glycol } \\ p K a & \text { Dissociation constant } \\ \text { PTH } & \text { Parathyroid hormone } \\ \text { PTHrP } & \end{array}$




\section{References}

1. Langer, R.; Vacanti, J.P. Tissue engineering. Science 1993, 260, 920-926. [CrossRef] [PubMed]

2. Leonidakis, K.A.; Soultan, A.H.; Piluso, S.; Kudva, A.K.; Van den Broeck, L.; Meiga, T.O.; Gibney, R.; Patterson. Biomimetic materials. In Concise Encyclopedia of Biomedical Polymers and Polymeric Biomaterials; Mishra, M.K., Ed.; CRC Press: Boca Raton, FL, USA, 2017; pp. 189-213.

3. Moreira Teixeira, L.S.; Patterson, J.; Luyten, F.P. Skeletal tissue regeneration: Where can hydrogels play a role? Int. Orthop. 2014, 38, 1861-1876. [CrossRef] [PubMed]

4. Buckwalter, J.A.; Mankin, H.J. Articular cartilage: Tissue design and chondrocyte-matrix interactions. Instr. Course Lect. 1998, 47, 477-486. [PubMed]

5. Patterson, J.; Martino, M.M.; Hubbell, J.A. Biomimetic materials in tissue engineering. Mater. Today 2010, 13, 14-22. [CrossRef]

6. Lutolf, M.P.; Hubbell, J.A. Synthetic biomaterials as instructive extracellular microenvironments for morphogenesis in tissue engineering. Nat. Biotechnol. 2005, 23, 47-55. [CrossRef] [PubMed]

7. Lutolf, M.P.; Lauer-Fields, J.L.; Schmoekel, H.G.; Metters, A.T.; Weber, F.E.; Fields, G.B.; Hubbell, J.A. Synthetic matrix metalloproteinase-sensitive hydrogels for the conduction of tissue regeneration: engineering cell-invasion characteristics. Proc. Natl. Acad. Sci. USA 2003, 100, 5413-5418. [CrossRef] [PubMed]

8. Bryant, S.J.; Durand, K.L.; Anseth, K.S. Manipulations in hydrogel chemistry control photoencapsulated chondrocyte behavior and their extracellular matrix production. J. Biomed. Mater. Res. Part A 2003, 67, 1430-1436. [CrossRef] [PubMed]

9. Bryant, S.J.; Chowdhury, T.T.; Lee, D.A.; Bader, D.L.; Anseth, K.S. Crosslinking density influences chondrocyte metabolism in dynamically loaded photocrosslinked poly(ethylene glycol) hydrogels. Ann. Biomed. Eng. 2004, 32, 407-417. [CrossRef] [PubMed]

10. Bryant, S.J.; Anseth, K.S. Hydrogel properties influence ECM production by chondrocytes photoencapsulated in poly(ethylene glycol) hydrogels. J. Biomed. Mater. Res. 2002, 59, 63-72. [CrossRef] [PubMed]

11. Bryant, S.J.; Bender, R.J.; Durand, K.L.; Anseth, K.S. Encapsulating chondrocytes in degrading PEG hydrogels with high modulus: Engineering gel structural changes to facilitate cartilaginous tissue production. Biotechnol. Bioeng. 2004, 86, 747-755. [CrossRef] [PubMed]

12. Liu, S.Q.; Tian, Q.; Hedrick, J.L.; Po Hui, J.H.; Ee, P.L.; Yang, Y.Y. Biomimetic hydrogels for chondrogenic differentiation of human mesenchymal stem cells to neocartilage. Biomaterials 2010, 31, 7298-7307. [CrossRef] [PubMed]

13. Lutolf, M.P.; Hubbell, J.A. Synthesis and physicochemical characterization of end-linked poly(ethylene glycol)-co-peptide hydrogels formed by Michael-type addition. Biomacromolecules 2003, 4, 713-722. [CrossRef] [PubMed]

14. Elbert, D.L.; Pratt, A.B.; Lutolf, M.P.; Halstenberg, S.; Hubbell, J.A. Protein delivery from materials formed by self-selective conjugate addition reactions. J. Control. Release 2001, 76, 11-25. [CrossRef]

15. Canal, T.; Peppas, N.A. Correlation between mesh size and equilibrium degree of swelling of polymeric networks. J. Biomed. Mater. Res. 1989, 23, 1183-1193. [CrossRef] [PubMed]

16. Metters, A.; Hubbell, J. Network formation and degradation behavior of hydrogels formed by Michael-type addition reactions. Biomacromolecules 2005, 6, 290-301. [CrossRef] [PubMed]

17. Raeber, G.P.; Lutolf, M.P.; Hubbell, J.A. Molecularly engineered PEG hydrogels: A novel model system for proteolytically mediated cell migration. Biophys. J. 2005, 89, 1374-1388. [CrossRef] [PubMed]

18. Patterson, J.; Hubbell, J.A. SPARC-derived protease substrates to enhance the plasmin sensitivity of molecularly engineered PEG hydrogels. Biomaterials 2011, 32, 1301-1310. [CrossRef] [PubMed]

19. Patterson, J.; Hubbell, J.A. Enhanced proteolytic degradation of molecularly engineered PEG hydrogels in response to MMP-1 and MMP-2. Biomaterials 2010, 31, 7836-7845. [CrossRef] [PubMed]

20. Roberts, S.J.; van Gastel, N.; Carmeliet, G.; Luyten, F.P. Uncovering the periosteum for skeletal regeneration: the stem cell that lies beneath. Bone 2015, 70, 10-18. [CrossRef] [PubMed]

21. Colnot, C.; Zhang, X.; Knothe Tate, M.L. Current insights on the regenerative potential of the periosteum: molecular, cellular, and endogenous engineering approaches. J. Orthop. Res. 2012, 30, 1869-1878. [CrossRef] [PubMed] 
22. Hayashi, O.; Katsube, Y.; Hirose, M.; Ohgushi, H.; Ito, H. Comparison of osteogenic ability of rat mesenchymal stem cells from bone marrow, periosteum, and adipose tissue. Calcif. Tissue Int. 2008, 82, 238-247. [CrossRef] [PubMed]

23. Sakaguchi, Y.; Sekiya, I.; Yagishita, K.; Muneta, T. Comparison of human stem cells derived from various mesenchymal tissues: superiority of synovium as a cell source. Arthritis Rheum 2005, 52, 2521-2529. [CrossRef] [PubMed]

24. Bolander, J.; Ji, W.; Geris, L.; Bloemen, V.; Chai, Y.C.; Schrooten, J.; Luyten, F.P. The combined mechanism of bone morphogenetic protein- and calcium phosphate-induced skeletal tissue formation by human periosteum derived cells. Eur. Cell Mater. 2016, 31, 11-25. [CrossRef] [PubMed]

25. Mendes, L.F.; Tam, W.L.; Chai, Y.C.; Geris, L.; Luyten, F.P.; Roberts, S.J. Combinatorial analysis of growth factors reveals the contribution of bone morphogenetic proteins to chondrogenic differentiation of human periosteal cells. Tissue Eng. Part C Methods 2016, 22, 473-486. [CrossRef] [PubMed]

26. Kudva, A.K.; Luyten, F.P.; Patterson, J. RGD-functionalized polyethylene glycol hydrogels support proliferation and in vitro chondrogenesis of human periosteum-derived cells. J. Biomed. Mater. Res. A 2018, 106, $33-42$. [CrossRef] [PubMed]

27. Peterson, L.; Vasiliadis, H.S.; Brittberg, M.; Lindahl, A. Autologous chondrocyte implantation: A long-term follow-up. Am. J. Sports Med. 2010, 38, 1117-1124. [CrossRef] [PubMed]

28. Kaur, G.; Dufour, J.M. Cell lines: Valuable tools or useless artifacts. Spermatogenesis 2012, 2, 1-5. [CrossRef] [PubMed]

29. Atsumi, T.; Miwa, Y.; Kimata, K.; Ikawa, Y. A chondrogenic cell line derived from a differentiating culture of AT805 teratocarcinoma cells. Cell Differ. Dev. 1990, 30, 109-116. [CrossRef]

30. Shukunami, C.; Ishizeki, K.; Atsumi, T.; Ohta, Y.; Suzuki, F.; Hiraki, Y. Cellular hypertrophy and calcification of embryonal carcinoma-derived chondrogenic cell line ATDC5 in vitro. J. Bone Miner. Res. 1997, 12, 1174-1188. [CrossRef] [PubMed]

31. Shukunami, C.; Shigeno, C.; Atsumi, T.; Ishizeki, K.; Suzuki, F.; Hiraki, Y. Chondrogenic differentiation of clonal mouse embryonic cell line ATDC5 in vitro: Differentiation-dependent gene expression of parathyroid hormone (PTH)/PTH-related peptide receptor. J. Cell Biol. 1996, 133, 457-468. [CrossRef] [PubMed]

32. Akiyama, H.; Shigeno, C.; Hiraki, Y.; Shukunami, C.; Kohno, H.; Akagi, M.; Konishi, J.; Nakamura, T. Cloning of a mouse smoothened cDNA and expression patterns of hedgehog signalling molecules during chondrogenesis and cartilage differentiation in clonal mouse EC cells, ATDC5. Biochem. Biophys. Res. Commun. 1997, 235, 142-147. [CrossRef] [PubMed]

33. Tare, R.S.; Howard, D.; Pound, J.C.; Roach, H.I.; Oreffo, R.O. Tissue engineering strategies for cartilage generation-Micromass and three dimensional cultures using human chondrocytes and a continuous cell line. Biochem. Biophys. Res. Commun. 2005, 333, 609-621. [CrossRef] [PubMed]

34. Lambrechts, D.; Roeffaers, M.; Kerckhofs, G.; Roberts, S.J.; Hofkens, J.; Van de Putte, T.; Van Oosterwyck, H.; Schrooten, J. Fluorescent oxygen sensitive microbead incorporation for measuring oxygen tension in cell aggregates. Biomaterials 2013, 34, 922-929. [CrossRef] [PubMed]

35. Weiss, H.E.; Roberts, S.J.; Schrooten, J.; Luyten, F.P. A semi-autonomous model of endochondral ossification for developmental tissue engineering. Tissue Eng. Part A 2012, 18, 1334-1343. [CrossRef] [PubMed]

36. Kwon, H.J.; Yasuda, K.; Ohmiya, Y.; Honma, K.; Chen, Y.M.; Gong, J.P. In vitro differentiation of chondrogenic ATDC5 cells is enhanced by culturing on synthetic hydrogels with various charge densities. Acta Biomater. 2010, 6, 494-501. [CrossRef] [PubMed]

37. Yu, F.; Cao, X.; Li, Y.; Zeng, L.; Yuan, B.; Chen, X. An injectable hyaluronic acid/PEG hydrogel for cartilage tissue engineering formed by integrating enzymatic crosslinking and Diels-Alder "click chemistry". Polym. Chem. 2014, 5, 1082-1090. [CrossRef]

38. Kudva, A.K.; Luyten, F.P.; Patterson, J. Initiating human articular chondrocyte re-differentiation in a 3D system after 2D expansion. J. Mater. Sci. Mater. Med. 2017, 28, 156. [CrossRef] [PubMed]

39. Ruoslahti, E.; Reed, J.C. Anchorage dependence, integrins, and apoptosis. Cell 1994, 77, 477-478. [CrossRef]

40. Kraehenbuehl, T.P.; Zammaretti, P.; Van der Vlies, A.J.; Schoenmakers, R.G.; Lutolf, M.P.; Jaconi, M.E.; Hubbell, J.A. Three-dimensional extracellular matrix-directed cardioprogenitor differentiation: Systematic modulation of a synthetic cell-responsive PEG-hydrogel. Biomaterials 2008, 29, 2757-2766. [CrossRef] [PubMed] 
41. Zustiak, S.P.; Durbal, R.; Leach, J.B. Influence of cell-adhesive peptide ligands on poly(ethylene glycol) hydrogel physical, mechanical and transport properties. Acta Biomater. 2010, 6, 3404-3414. [CrossRef] [PubMed]

42. Vigen, M.; Ceccarelli, J.; Putnam, A.J. Protease-sensitive PEG hydrogels regulate vascularization in vitro and in vivo. Macromol. Biosci. 2014, 14, 1368-1379. [CrossRef] [PubMed]

43. Van den Broeck, L.; Piluso, S.; Soultan, A.H.; De Volder, M.; Patterson, J. Cytocompatible carbon nanotube reinforced polyethylene glycol composite hydrogels for tissue engineering. 2018; under revision.

44. Engler, A.J.; Sen, S.; Sweeney, H.L.; Discher, D.E. Matrix elasticity directs stem cell lineage specification. Cell 2006, 126, 677-689. [CrossRef] [PubMed]

45. Lin, S.; Sangaj, N.; Razafiarison, T.; Zhang, C.; Varghese, S. Influence of physical properties of biomaterials on cellular behavior. Pharm. Res. 2011, 28, 1422-1430. [CrossRef] [PubMed]

46. Liao, H.; Munoz-Pinto, D.; Qu, X.; Hou, Y.; Grunlan, M.A.; Hahn, M.S. Influence of hydrogel mechanical properties and mesh size on vocal fold fibroblast extracellular matrix production and phenotype. Acta Biomater. 2008, 4, 1161-1171. [CrossRef] [PubMed]

47. Papantoniou, I.; Sonnaert, M.; Lambrechts, T.; Aerts, J.-M.; Geris, L.; Luyten, F.; Schrooten, J. Analysis of gene expression signatures for osteogenic 3D perfusion-bioreactor cell cultures based on a multifactorial DoE approach. Processes 2014, 2, 639-657. [CrossRef]

48. Maia, F.R.; Lourenco, A.H.; Granja, P.L.; Goncalves, R.M.; Barrias, C.C. Effect of cell density on mesenchymal stem cells aggregation in RGD-alginate 3D matrices under osteoinductive conditions. Macromol. Biosci. 2014, 14, 759-771. [CrossRef] [PubMed]

49. Kudva, A.K.; Dikina, A.D.; Luyten, F.P.; Alsberg, E.; Patterson, J. Gelatin microspheres releasing transforming growth factor drive in vitro chondrogenesis of human periosteum derived cells in micromass culture. 2018; submitted.

50. Elisseeff, J. Injectable cartilage tissue engineering. Expert Opin. Biol. Ther. 2004, 4, 1849-1859. [CrossRef] [PubMed]

51. Jin, R.; Moreira Teixeira, L.S.; Dijkstra, P.J.; Karperien, M.; van Blitterswijk, C.A.; Zhong, Z.Y.; Feijen, J. Injectable chitosan-based hydrogels for cartilage tissue engineering. Biomaterials 2009, 30, 2544-2551. [CrossRef] [PubMed]

52. Jin, R.; Teixeira, L.S.; Dijkstra, P.J.; van Blitterswijk, C.A.; Karperien, M.; Feijen, J. Enzymatically-crosslinked injectable hydrogels based on biomimetic dextran-hyaluronic acid conjugates for cartilage tissue engineering. Biomaterials 2010, 31, 3103-3113. [CrossRef] [PubMed]

53. Bryant, S.J.; Anseth, K.S.; Lee, D.A.; Bader, D.L. Crosslinking density influences the morphology of chondrocytes photoencapsulated in PEG hydrogels during the application of compressive strain. J. Orthop. Res. 2004, 22, 1143-1149. [CrossRef] [PubMed]

54. Hyllested, J.L.; Veje, K.; Ostergaard, K. Histochemical studies of the extracellular matrix of human articular cartilage-A review. Osteoarthritis Cartilage 2002, 10, 333-343. [CrossRef] [PubMed]

55. Junqueira, L.C.; Bignolas, G.; Brentani, R.R. Picrosirius staining plus polarization microscopy, a specific method for collagen detection in tissue sections. Histochem. J. 1979, 11, 447-455. [CrossRef] [PubMed]

56. Lattouf, R.; Younes, R.; Lutomski, D.; Naaman, N.; Godeau, G.; Senni, K.; Changotade, S. Picrosirius red staining: A useful tool to appraise collagen networks in normal and pathological tissues. J. Histochem. Cytochem. 2014, 62, 751-758. [CrossRef] [PubMed]

57. Eyckmans, J.; Roberts, S.J.; Schrooten, J.; Luyten, F.P. A clinically relevant model of osteoinduction: A process requiring calcium phosphate and BMP/Wnt signalling. J. Cell. Mol. Med. 2010, 14, 1845-1856. [CrossRef] [PubMed]

58. Lin, H.; Cheng, A.W.; Alexander, P.G.; Beck, A.M.; Tuan, R.S. Cartilage tissue engineering application of injectable gelatin hydrogel with in situ visible-light-activated gelation capability in both air and aqueous solution. Tissue Eng. Part A 2014, 20, 2402-2411. [CrossRef] [PubMed]

(C) 2018 by the authors. Licensee MDPI, Basel, Switzerland. This article is an open access article distributed under the terms and conditions of the Creative Commons Attribution (CC BY) license (http://creativecommons.org/licenses/by/4.0/). 